\title{
A decision support tool for integrated fisheries bycatch management
}

\author{
Eric Gilman (D) - Martin Hall (D) - Hollie Booth - Trisha Gupta - Milani Chaloupka (D) \\ Hannah Fennell • Michel J. Kaiser (D) Divya Karnad - E. J. Milner-Gulland
}

Received: 6 August 2021 / Accepted: 27 November 2021 / Published online: 21 January 2022

(C) The Author(s) 2022

\begin{abstract}
Participatory decision tools enable stakeholders to reconcile conflicting natural resources management objectives. Fisheries targeting highly productive species can have profound impacts on cooccurring bycatch species with low fecundity and other life history traits that make them vulnerable to anthropogenic sources of mortality. This study developed a decision tool for integrated bycatch management for data-limited to data-rich fisheries, improving upon current piecemeal approaches. First, through a systematic literature review, participants compile a
\end{abstract}

E. Gilman $(\bowtie)$

Pelagic Ecosystems Research Group, Honolulu, USA

e-mail: FisheriesResearchGroup@gmail.com

E. Gilman · H. Fennell · M. J. Kaiser

The Lyell Centre, Heriot-Watt University, Edinburgh, UK

M. Hall

Inter-American Tropical Tuna Commission, La Jolla, USA

H. Booth · T. Gupta · E. J. Milner-Gulland

Department of Zoology, University of Oxford, Oxford, UK

\section{Chaloupka}

Ecological Modelling Services Pty Ltd and Marine Spatial Ecology Lab, University of Queensland, Brisbane,

Australia

D. Karnad

Ashoka University, Sonipat, India comprehensive database of methods to mitigate the catch and fishing mortality of threatened bycatch species. These mitigation methods are then categorized into tiers of a sequential mitigation hierarchy, where interventions that avoid capture are considered before those that minimize catchability, followed by methods that minimize fishing mortality, before approaches that offset residual impacts. The methods are also assembled within an evidence hierarchy, where findings from meta-analytic modelling studies are more robust and generalizable than from individual studies. The decision tool enables stakeholders to evaluate alternative bycatch management strategies' efficacy at meeting specific and measurable objectives for mitigating the catch and mortality of bycatch and for costs from multispecies conflicts, economic viability, practicality and safety, while accounting for the fishery-specific feasibility of compliance monitoring of alternative bycatch management measures. Ongoing adaptation of the bycatch management framework addresses findings from performance assessments, updated evidence, new mitigation methods and changes to governance systems. The proposed decision tool therefore enables stakeholders to develop bycatch management frameworks that provide precautionary protection for the most vulnerable populations with acceptable tradeoffs.

Keywords Bycatch - Decision tool - Economic viability $\cdot$ Evidence hierarchy $\cdot$ Mitigation hierarchy 


\section{Introduction}

Overexploitation is the primary cause of recent marine species extinctions, and causes protracted or irreparable harm and permanent loss of populations, with consequences across manifestations of biodiversity and ecosystem services, including fishery yields (Pereira et al. 2010; McCauley et al. 2015; Pacoureau et al. 2021). Incidental mortality or bycatch ${ }^{1}$ in fisheries is the largest threat to many populations of marine megafauna and an obstacle to sustainable seafood production. Fisheries targeting highly productive species can have profound impacts on cooccurring species also susceptible to capture that have long generation lengths, low fecundity and other life history traits that make them vulnerable to anthropogenic sources of mortality. Their populations can decline quickly and once depleted, have limited recovery potential (Musick 1999; Hall et al. 2000; Chaloupka 2002; Dulvy et al. 2017).

Some species of chondrichthyans (sharks, rays and chimaeras), marine turtles, sea snakes, marine mammals, seabirds and teleosts are threatened with extinction due to bycatch (Wallace et al. 2013; Davidson et al. 2015; Phillips et al. 2016; Gray and Kennelly 2018; Dias et al. 2019; Lopez-Mendilaharsu et al. 2020; Nelms et al. 2021; Pacoureau et al. 2021). Depending on a fishery's management framework and markets, some of these species may be targeted, retained incidental catch (including retention of shark fins and manta and devil ray gill plates and discarding of the remaining carcass) or discarded (Elfes et al. 2013; Cao et al. 2014; O’Malley et al. 2016; Dulvy

\footnotetext{
${ }^{1}$ We define unwanted bycatch as the catch and fishing mortality of species, and in some cases, sizes and sex, that stakeholders aim to avoid, minimize and offset in order to address ecological and socioeconomic objectives. Because of the broad diversity in global fisheries, including in their markets, management frameworks and fisher practices, the definition of bycatch will vary broadly by individual fishery and over time. There is tremendous variability in bycatch definitions, including those adopted by different nations, in fishery-specific management plans and regulations, and in publications. For example, disparate bycatch definitions applied to tuna fisheries have included: species other than tunas (small-scale tuna fisheries, Gillett 2011); dead discards (purse seine fisheries, Hall and Roman 2013); and species other than tuna and tuna-like species and billfishes (longline fisheries, Clarke et al. 2014). As a result, the Food and Agriculture Organization of the United Nations (FAO) has deemed it impossible to adopt a standard international definition of bycatch (FAO 2011).
}

et al. 2017; Hall et al. 2017). There is extremely limited understanding of the conservation status of most teleost bycatch species due to poor data quality and few assessments. However, the conservation status and threat from bycatch of some vulnerable teleosts are relatively well understood, such as for seahorses, where substantial bycatch occurs in seine and shrimp-trawl fisheries (Gray and Kennelly 2018; Vaidyanathan et al. 2021).

For some gear types and some taxa of vulnerable bycatch, numerous methods are now available that avoid and substantially reduce catch and fishing mortality that are also economically viable, practical, safe and enable compliance monitoring, although there has been mixed progress in their uptake (Clarke et al. 2014; Gilman et al. 2014; Davidson et al. 2015; Hall et al. 2017). Furthermore, fragmented, piecemeal bycatch management systems, with separate taxonspecific measures, can cause unintended multispecies conflicts (Gilman et al. 2019a). Some methods that mitigate the catch and mortality of one vulnerable bycatch species exacerbate the catch and mortality of others. This includes acoustic pingers, changes to hook shape, fishing depth and area-based management tools such as no-take marine protected areas (Gilman et al. 2019a). There is a pressing need for a participatory decision tool to support fisheries stakeholders to discover and adopt appropriate combinations of mitigation methods in order to develop or strengthen integrated bycatch management systems to meet their objectives, including on acceptable costs resulting from multispecies conflicts. Participatory decisionmaking tools can assist fisheries stakeholders to balance competing objectives related to managing vulnerable bycatch, where interest groups place disparate importance on the economic, social and ecological components of the triple-bottom-line (Elkington 1994; Halpern et al. 2013; Abbott et al. 2014).

To fill this gap, we developed a participatory decision support tool for stakeholders to manage the ecological risks of fisheries bycatch. The tool employs sequential mitigation and evidence hierarchies, and accounts for the efficacy of alternative methods at meeting objectives for mitigating the catch and fishing mortality of vulnerable bycatch. It enables stakeholders to assess whether alternative management strategies meet their objectives on acceptable costs from cross-taxa conflicts and from reductions in practicality, safety and economic viability. The tool accounts 
for the feasibility of monitoring compliance with bycatch mitigation methods given both the effect of crew behavior on the performance of mitigation methods and the capacity of the fisheries management system. The tool enables stakeholders to identify management interventions that provide precautionary protection for the most vulnerable catch, and to select a management strategy with acceptable multispecies conflicts and commercial viability costs.

\section{Decision tool scope and components}

The decision tool supports stakeholders to establish and meet objectives for managing the effects of fishing on vulnerable bycatch species. For convenience, we use 'bycatch management' and 'bycatch mitigation' to refer to interventions that affect the catchability and all sources of fishing mortality (i.e., all components of direct and collateral fishery removals, defined in Section Sequential Bycatch Mitigation Hierarchy) of vulnerable bycatch species.

The decision tool employs an integrated approach by accounting for cross-taxa effects of alternative bycatch mitigation methods, improving upon prevailing piecemeal, taxa-specific designs of bycatch management systems (Gilman et al. 2019a). The tool can be applied at a narrow scale for fishery-specific bycatch management and at a nested-scale to manage cumulative bycatch by regional fisheries. The tool is designed for application across data-limited to datarich fisheries, from artisanal/small-scale to industrial/ large scale fisheries, across gear types. And, it is designed for use across the various forms of fisheries management systems, ranging from government command-and-control frameworks with model-based stock assessments and input and output controls typical of data-rich, large-scale fisheries, to informal community-based self-governance and co-management frameworks with territorial use rights and indicator-based rules typical of data-limited, smallscale fisheries (Christy 1982; Pomeroy et al. 2010; Kolding et al. 2014). The presentation of the decision support tool in this article is designed for use by subject matter experts in bycatch mitigation science and policy who would lead or provide advice on implementing the tool.

The decision tool components are summarized in Fig. 1. The tool is based on previous approaches to multi-stakeholder, participatory management of natural resources (Elkington 1994; Halpern et al. 2013; Abbott et al. 2014; Milner-Gulland et al. 2018; Arlidge et al. 2020; Booth et al. 2020). First, through systematic and unstructured literature reviews, a comprehensive dataset of mitigation measures for catch and mortality of vulnerable bycatch species is compiled for the gear type of interest. The mitigation methods are categorized within pre-defined sequential mitigation and evidence hierarchies. Then, stakeholders participating in implementing the decision support tool follow steps to plan and initiate implementing an integrated bycatch management framework. Stakeholders periodically adapt the bycatch management system to address findings from performance assessments and updated and more certain risk assessments, changes in the fishery and catch, and to account for new bycatch mitigation methods and improved evidence of efficacy as new research findings accumulate. These adaptions gradually improve the efficacy of the integrated bycatch management framework. The following sections provide guidance to implement each of these steps.

\section{Comprehensive database of bycatch mitigation methods}

Systematic literature review and exhaustive database of bycatch mitigation methods

If an exhaustive and current database of bycatch mitigation methods for the gear type of interest is unavailable, then a systematic literature review should be conducted or updated to produce one. Systematic reviews employ an impartial, transparent and thus replicable approach, and reduce the risk of biased selection of publications (we use 'publications' to refer to all studies irrespective of their publication status) and concomitant risks of introducing prevailing paradigm, familiarity, citation and publication biases (Sutton 2009; CEE 2013; Bayliss and Beyer 2015). If resource limitations prevent conducting a systematic review, then stakeholders can rely on publications that employed targeted, non-systematic reviews. This approach, however, has a high risk of bias and can lead to erroneous conclusions, and is therefore discouraged. 


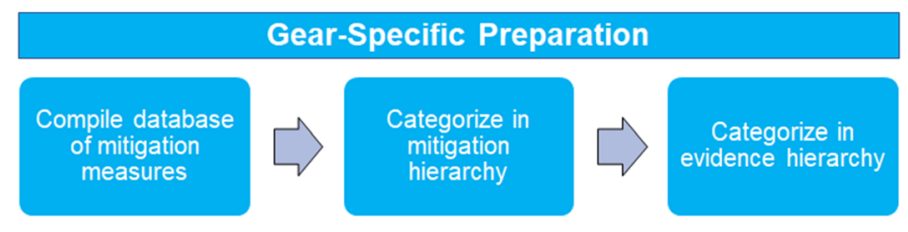

Fishery-Specific Planning and Implementation

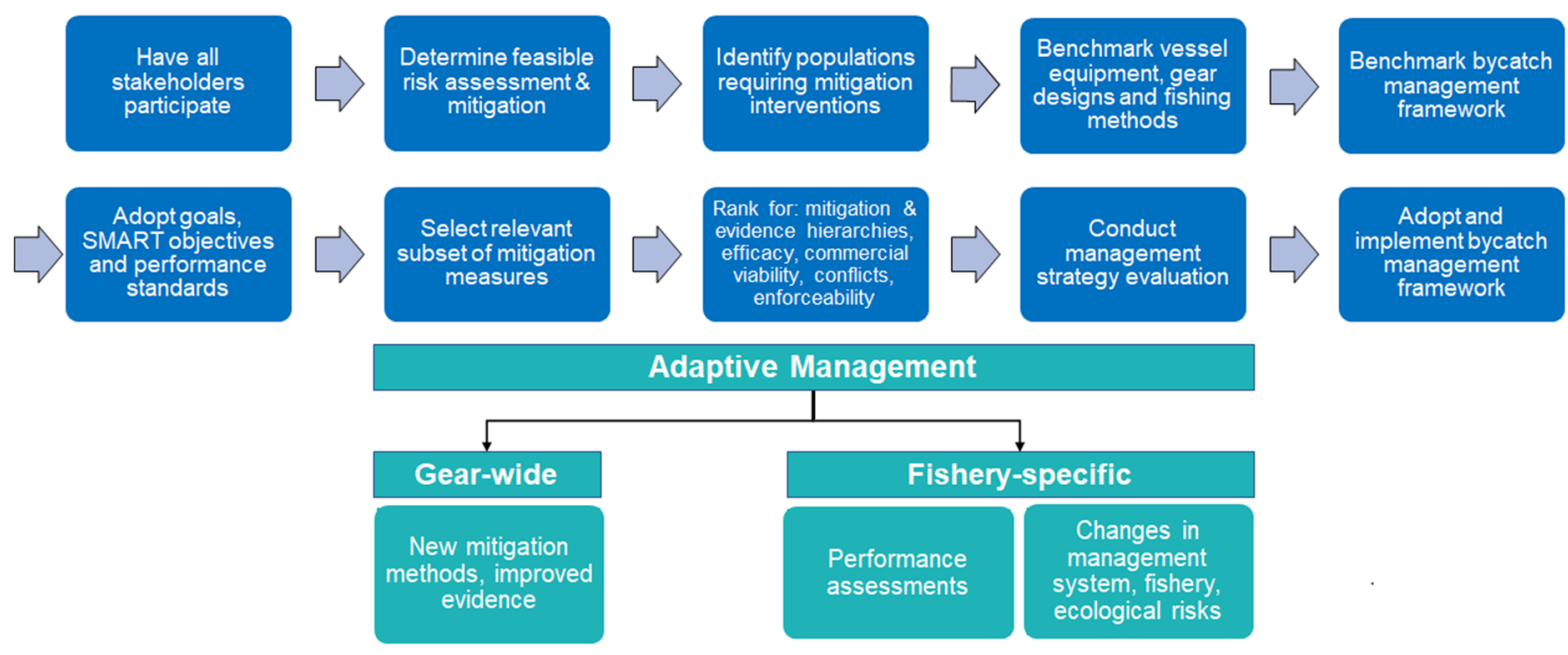

Fig. 1 Components of the decision tool for integrated management of the catch and fishing mortality of vulnerable bycatch species

The methods for planning, implementing and reporting the systematic review should follow the Reporting standards for systematic evidence syntheses (ROSES, Haddaway et al. 2018), Collaboration for Environmental Evidence (CEE, Pullin et al. 2020, 2021), or otherwise Preferred Reporting Items for Systematic reviews and Meta-Analyses (PRISMA, Page et al. 2021a,b), but adapting the PRISMA checklist into a reporting protocol. ROSES and CEE were designed for conservation and environmental management reviews, while PRISMA was designed for medical reviews, but they contain similar data fields. The systematic review protocol could be published as a standalone article in the journal Environmental Evidence. An unstructured literature search may also be conducted to complement the systematic review, such as by reviewing reference lists of publications compiled during the systematic search (snowballing, Pullin et al. 2020) and by inquiring with relevant subject matter experts. The resulting database could be published so that it is discoverable and can be updated.

The compiled literature is then screened against explicit eligibility criteria for retention. Publications that describe a method, or combination of methods, that mitigates the risk of capture or one or more component of total fishing mortality rate (discussed in the next section) of vulnerable species, or that offsets residual bycatch mortalities, in the gear type of interest, should be retained. While the systematic review should be designed to discover studies specific to the gear type used in the fishery for which the bycatch management plan is being developed, records for some bycatch mitigation methods that are not gear specific should also be retained. This may include, for example, mechanistic studies (e.g., shark behavioral responses to repellants), input controls on fishing effort, output controls such as bycatch quotas, changing gear type, dynamic and static area-based management tools, fleet communication, methods to mitigate the production and adverse consequences of derelict fishing gear, and approaches for bycatch offsets. As described in the Evidence Hierarchy section, retained studies are categorized according to tiers in an evidence hierarchy. We do not, however, recommend excluding publications based on a study design eligibility criterion as this might prevent detecting alternative bycatch mitigation methods. For the same 
reason, published and grey literature should not be required to have been peer reviewed.

Approaches to reduce the risk of introducing bias should be followed to the extent that resources permit. Grey literature and all hits (and not, for instance, limiting results to the first 100 hits, which may be sorted by number of citations) should be included (Sutton 2009; CEE 2013; Bayliss and Beyer 2015). For example, a study with negative or non-significant findings may not be highly cited or published and hence runs the risk of not being identified through searches that limit the number of returned publications or exclude grey literature, respectively, but is important evidence. Not restricting the geography, time period or language of publications, and employing consistency checks for screening and data extraction from retained publications, are additional protocols to contribute to producing unbiased results from systematic reviews (Bayliss and Beyer 2015; Haddaway et al. 2018; Pullin et al. 2020, 2021).

Each record in the database of references of retained results from the systematic and unstructured literature reviews should, at a minimum, contain data fields on: (1) evidence hierarchy category (see Evidence Hierarchy section), (2) bycatch mitigation methods assessed in the study, (3) bycatch species groups that were assessed, and (4) a summary of the response of each species group to the treatment. Using the database of retained records, participants will produce a summary table that provides an exhaustive, comprehensive database of bycatch mitigation methods identified in the compiled literature. Supplemental Material Table S1 is an illustrative example, with four sample records relevant to pelagic longline fisheries of bycatch limits, move-on rules, weak hooks and wider circle vs. narrower J-shaped hooks. Section S3 provides definitions of the data fields of Table S1.

A second table, designed for a broad lay audience of fisheries stakeholders, provides a high-level overview of options, relative degree of evidence and potential costs from multispecies conflicts and reduced commercial viability. Table 1 is an illustrative example, and uses the same sample records included in Table S1. Table 1 provides a simplified overview of species group-specific catch and fishing mortality responses to bycatch mitigation measures, with information on the sample size of publications in evidence hierarchy categories $1-5$. Prototype mitigation methods that both lack quantitative evidence of efficacy and are not in commercial use should be excluded from Table 1 . The same rule employed in Table $\mathrm{S} 1$ for listed citations, defined in Section S3, is followed in Table 1.

While most records in Tables S1 and 1 will be for individual bycatch mitigation methods, combinations of methods are typically required to maximize efficacy and meet objectives. For example, ACAP (2019) identified the simultaneous use of three methods as the most effective approach to mitigate seabird bycatch in demersal longline fisheries. Records for combinations of methods where synergistic, interacting effects have been documented should be included. For instance, the time-of-day of fishing operations and fishing depth determine encounterability and catch risk for pelagic predators whose vertical distributions vary temporally due to diel vertical migration cycles, time of day of foraging and temporal variability in diving behavior (Musyl et al. 2011; Clarke et al. 2014; Gilman et al. 2019a). Pelagic longline hook type, bait type and leader material provide a second example of the synergistic effects of gear components on catch risk: Hook shape and size and bait type can affect anatomical hooking position and the ability of some species to escape when monofilament leaders are used, but not when more durable wire and multifilament leader materials are used (Clarke et al. 2014; Gilman et al. 2016a).

In some cases, participants implementing the decision support tool may benefit from more in-depth assessments of a candidate bycatch mitigation method. This may be warranted when participants are divided on the adoption of the measure, if they are unclear on whether the method will meet their objectives for bycatch mitigation and acceptable costs from multispecies conflicts and commercial viability tradeoffs, and whether the fisheries management system supports robust compliance monitoring. Examples of brief narrative syntheses, suitable for presentation to stakeholders implementing the decision support tool, are included in Supplemental Material Sections S1 and S2 for weak hooks and bycatch quotas for pelagic longline fisheries, respectively.

Sequential bycatch mitigation hierarchy

The comprehensive suite of alternative bycatch mitigation methods can be categorized into four tiers of a sequential mitigation hierarchy of: 
Table 1 Illustrative format suitable for a broad lay audience of fisheries stakeholders to relay a high-level overview of bycatch mitigation method options for pelagic longline fisheries, species group-specific effects on catch and fishing mortality rates, commercial viability, and compliance monitoring requirements. Methods are sorted into taxonomic groups for which they are typically prescribed as a bycatch mitigation approach, and then by mitigation hierarchy tier. For each method, the first row is catch rate response, and the second row is fishing mortality rate response. Commercial use refers to whether the approach is in use, either voluntarily or through a binding measure, in one or more pelagic longline fishery. $\Delta=$ quantitative evidence that the method reduces pelagic longline catch or fishing mortality risk; $-=$ no effect; $\nabla=$ increases catch or mortality risk; ? = inconclusive; $\mathrm{V}=$ variable response; $\approx=$ high risk; $\leftleftarrows=$ medium risk; $₫=$ low risk

\begin{tabular}{|c|c|c|c|c|c|c|c|c|c|}
\hline Method & Cetaceans & $\begin{array}{c}\text { Turtles- } \\
\text { hardshelled }\end{array}$ & $\begin{array}{c}\text { Turtles- } \\
\text { leatherback }\end{array}$ & Rays & Seabirds & $\begin{array}{c}\text { Sharks- } \\
\text { epipelagic }\end{array}$ & $\begin{array}{c}\text { Sharks- } \\
\text { mesopelagic }\end{array}$ & Teleosts & $\begin{array}{c}\text { Mitigation } \\
\text { hierarchy tiers }\end{array}$ \\
\hline \multirow{3}{*}{ Bycatch limit ${ }^{3}$} & & & & & & & & & \\
\hline & $?$ & $\boldsymbol{\Delta}$ & $\boldsymbol{\Delta}$ & $?$ & $?$ & $?$ & $?$ & $?$ & Avoid catch \\
\hline & - & - & - & - & - & - & - & - & NA \\
\hline \multirow{2}{*}{ Move-on } & $\boldsymbol{\Delta}$ & $\boldsymbol{\Delta}$ & $\Delta$ & $?$ & $?$ & $?$ & $?$ & $?$ & Avoid catch \\
\hline & - & - & - & - & - & - & - & - & NA \\
\hline \multicolumn{10}{|l|}{ Cetaceans } \\
\hline \multirow{2}{*}{ Weak hook } & $?$ & - & - & - & - & $\boldsymbol{\nabla}$ & $\nabla$ & $v^{4}$ & Minimize catch \\
\hline & $?$ & - & - & - & - & $?$ & $?$ & $?$ & Minimize mortality \\
\hline \multicolumn{10}{|l|}{ Marine turtles } \\
\hline \multirow{2}{*}{$\begin{array}{l}\text { Wider circle } \\
\text { v. narrower J- } \\
\text { shaped hook }\end{array}$} & $\boldsymbol{\Delta}$ & $\boldsymbol{\Delta}$ & $\Delta$ & $\Delta$ & $\Delta^{5}$ & $\nabla$ & $\nabla$ & V & Minimize catch \\
\hline & $\nabla$ & $\Delta$ & $\Delta$ & - & - & $\Delta$ & $\Delta$ & $\Delta$ & Minimize mortality \\
\hline
\end{tabular}

\begin{tabular}{|c|c|c|c|c|c|c|c|}
\hline Method & $\begin{array}{c}n \\
\text { EH } \\
1-5^{2}\end{array}$ & $\begin{array}{c}\text { Commercial } \\
\text { use }\end{array}$ & $\begin{array}{l}\text { Economic } \\
\text { cost risk }\end{array}$ & $\begin{array}{c}\text { Practicality } \\
\text { risk }\end{array}$ & $\begin{array}{l}\text { Safety } \\
\text { risk }\end{array}$ & $\begin{array}{c}\text { Compliance } \\
\text { monitoring } \\
\text { requires } \\
\text { observer or EM }\end{array}$ & Top EH citations \\
\hline \multicolumn{8}{|l|}{ Inter-taxa } \\
\hline Bycatch limit $^{3}$ & 0 & Y & - & - & - & Y & $\begin{array}{l}\text { Australian Antarctic Division 2018; } \\
\text { WCPFC 2009, 2018a; NMFS 2020a,b } \\
\text { Gilman et al. 2007: Gardner et al. 2008. }\end{array}$ \\
\hline Move-on & 4 & Y & - & - & - & Y & $\begin{array}{l}\text { Forney et al. 2011; Ayers and Leong 2020; } \\
\text { Fader et al. 2021a }\end{array}$ \\
\hline \multicolumn{8}{|l|}{ Cetaceans } \\
\hline Weak hook & 1 & Y & - & - & - & Y & $\begin{array}{l}\text { Bayse and Kerstetter 2010; Bigelow et al. } \\
\text { 2012; Foster and Bergmann 2012; } \\
\text { McLellan et al. 2015; NMFS 2019 }\end{array}$ \\
\hline \multicolumn{8}{|l|}{ Marine turtles } \\
\hline $\begin{array}{l}\text { Wider circle v. } \\
\text { narrower J- } \\
\text { shaped hook }\end{array}$ & $>50$ & $\mathrm{Y}$ & - & - & - & $\mathrm{N}$ & $\begin{array}{l}\text { Godin et al. 2012; Favaro and Cote 2015; } \\
\text { Gilman et al. 2016a; Reinhardt et al. 2018; } \\
\text { Rosa et al. } 2020\end{array}$ \\
\hline
\end{tabular}

${ }^{1}$ Mitigation hierarchy tiers and components:

Avoid catch = Eliminate catchability of one or more bycatch species or assemblage completely within the scope of the intervention Minimize catch $=$ Reduce catchability of one or more bycatch species or assemblage

Avoid mortality = Eliminate fishing mortality risk of one or more bycatch species or assemblage completely within the scope of the intervention Minimize mortality = Reduce fishing mortality risk of one or more bycatch species or assemblage

Offset = Obtain an equivalent gain to replace any residual fishing mortality, or obtain a net gain

${ }^{2} n$ EH 1-5 = Sample size of compiled publications in evidence hierarchy quantitative tiers 1-5 with findings on efficacy at mitigating bycatch or mortality rate

${ }^{3}$ Measures that reduce effort can avoid bycatch for all taxonomic groups when designed accordingly (e.g., see caveats for bycatch quotas, Sup. Material Section S2), however, in Table 1, only species for which there was quantitative evidence of a response are categorized as $\boldsymbol{\Delta}$

${ }^{4}$ Reduces catch risk of unwanted bluefin tuna (Foster and Bergmann 2012) but may also reduce catch risk of targeted and incidental marketable species (e.g., bigeye tuna, spearfish) (Bigelow et al. 2012), and due to required use of more durable leaders, may increase catch of some shark and unwanted teleost species by reducing their ability to sever the line

${ }^{5}$ Two studies found no significant difference in albatross catch rates between wider circle and narrower J-shaped hooks (Domingo et al. 2012; Gilman et al. 2016c). Two studies observed that wider circle hooks had lower catch rates of primarily gulls (Laridae) and shearwaters (Procellariidae) than narrower J-shaped hooks, (Hata 2006; Li et al. 2012). This suggests that catch risk response to hook type may only be important for relatively small seabird species 
1. Avoid the risk of capture;

2. Minimize the risk of capture;

3. Remediate one or more component of total fishing mortality (defined below); and

4. Offset residual bycatch mortalities.

There are now several theoretical, mostly taxonspecific illustrations of the utility of applying a sequential mitigation hierarchy framework to manage fisheries bycatch (Wilcox and Donlan 2007; Hall 2015; Milner-Gulland et al. 2018; Squires et al. 2018; Arlidge et al. 2020; Booth et al. 2020). Measures to avoid unwanted bycatch completely prevent one or more extrinsic factor that influences capture risk, referred to as susceptibility or catchability attributes. These attributes include areal overlap, encounterability and selectivity (Stobutzki et al. 2002; Hobday et al. 2011). For example, a fishery that changes their gear type from driftnet to troll can eliminate leatherback turtle bycatch (Eckert et al. 2008). Area-based management tools, ranging from static and permanent notake marine protected areas to temporally- and spatially-dynamic closures, may avoid bycatch risk of a vulnerable species by eliminating areal or temporal overlap between fishing vessels and a species' distribution (Hobday et al. 2010; Little et al. 2015).

Bycatch minimization methods reduce one or more capture susceptibility attribute. Bycatch minimization methods can be broadly categorized as: (1) input controls on effort and output controls on catch levels or rates that indirectly also reduce fishing effort, and (2) measures that involve changes in fishing methods and gear designs that reduce areal overlap, reduce encounterability or increase selectivity to reduce bycatch rates (Hall 1996; Pascoe et al., 2010; Hall et al. 2017). Limited entry and buyback programs that reduce fishing capacity are examples of bycatch minimization approaches. Area-based management tools that reduce (but do not eliminate) areal or temporal overlap are another example. Changes in gear designs and fishing methods can be categorized according to their mechanism for reducing bycatch catchability (Broadhurst 2000; Gilman et al. 2005; Werner et al. 2006; Hall 2015; Willems et al. 2016; FAO 2016; Darquea et al. 2020):

- Reducing areal (i.e., horizontal, geospatial) overlap;
- Reducing depth overlap (e.g., deploying drift gillnets below the sea surface to avoid seabirds);

- Reducing temporal overlap, such as by adjusting the season and time-of-day of fishing effort, reducing the duration of individual fishing operations, and increasing baited hook sink rates to reduce seabird interactions;

- Increasing selectivity due to morphological characteristics (e.g., Turtle Excluder Devices, sorting and shepherding devices used in shrimp and prawn trawl fisheries exclude marine turtles and large fishes, including elasmobranchs, while largely retaining smaller organisms, including targeted shrimp, that fit through the grid; organism's mouth dimensions may reduce the probability of ingesting a wider hook), or design of a gear component (e.g., eliminating or reducing the length of anchored gillnet tiedowns reduces the risk of marine turtle entanglement, and reducing or eliminating buoy lines of fixed gear such as pots and gillnets reduces whale entanglement risk);

- Increasing escapement (e.g., turtle excluder devices in trawls, weak links and lower breakingstrength lines in traps and gillnets, and backdown procedure by tuna purse seine vessels to release dolphins from the net);

- Reducing gear detection (e.g., camouflaged gear and dyed bait);

- Increasing gear detection (e.g., pingers to reduce bycatch rates of some cetaceans and seabirds in gillnet, trawl, trap and other gear types; and making portions of gillnets more visible using certain net colors, using thicker twine, attaching corks or other materials and illumination to reduce catch rates of marine turtles, seabirds and marine mammals);

- Shielding the gear to limit access (e.g., streamer tori lines and underwater setting devices);

- Repelling predators (e.g., acoustic, electrical, chemical, magnetic and rare earth electropositive metals); and

- Reducing the attractiveness of the gear (e.g., bait species and artificial bait).

The next step in the bycatch mitigation hierarchy is to reduce the probability of fishing mortality. The components of total fishing mortality are (ICES 2005; Gilman et al. 2013): 
- Pre-catch losses, where an organism that escapes prior to capture dies as a result of the fishing operation;

- Retained catch;

- Dead discards;

- Ghost-fishing mortality by fishing gear that was abandoned, lost or discarded;

- Post-release mortality of catch that is retrieved and then released alive but later dies as a result of stress and injury sustained from the fishing interaction; and

- Collateral (also referred to as unaccounted or cryptic) mortalities indirectly caused by various effects of fishing.

For the first five components, there are well-documented measures available to reduce the probability of mortality. For example, for species susceptible to capture by ingesting a hook, the use of circle-shaped hooks can increase the probability of pre-catch, atvessel and post-release survival relative to J-shaped hooks (Hall et al. 2017). Bans on shark finning, where fins are retained and the remaining carcass is discarded, might reduce the retention of sharks lacking market value other than for fins, which in turn might reduce fishing mortality. However, for species that are retained for their meat and other products, finning bans may not affect fishing mortality rates (Clarke et al. 2013). Retention bans have been documented to reduce fishing mortality in some fisheries (Gilman et al. 2016b), but may not be effective under certain legal and regulatory frameworks (Tolotti et al. 2015; Ward-Paige 2017). Most of the factors that affect the survival rates of live releases also affect escapees, including their duration on the gear, fishing depth, anatomical hooking location, and in towed nets, the catch size and composition (Gilman et al. 2013). Handling and release methods and gear remaining attached (e.g., length of trailing line on sharks and marine turtles, Parga 2012; FAO 2019) also affect the probability of post-release survival. There are many methods to mitigate the production and adverse effects of Abandoned, lost and discarded fishing gear (ALDFG), including ghost fishing, such as temporal and spatial separation of mobile and static gear, and using biodegradable gear components (Macfadyen et al. 2009).

Indirect, collateral sources of fishing mortality, however, are more challenging to document as well as to mitigate (ICES 2005; Uhlmann and Broadhurst 2015). For example, collateral fishing mortalities can result from (Estes et al. 2011; Gilman et al. 2013; Heino et al. 2015):

- Facilitated predation, where escapees and live released catch are predated before they are able to return to their preferred habitat or because the interaction with fishing operations impaired their behavior;

- Reduced school sizes can reduce the fitness of remaining individuals by increasing the risk of predation and reducing the efficiency in mating, foraging and energy expenditure;

- Cumulative stress and injury caused by repeated sublethal effects of fishing;

- Habitat degradation and alteration by fishing;

- Disease in organisms injured or killed by fishing operations;

- Reduced abundance of tunas and other pelagic apex predators, which bring baitfish to the surface, decreases the availability of prey to seabirds, contributing to increased vulnerability to starvation and other stressors that could result in mortality;

- Fisheries-induced evolution, which alters the evolutionary characteristics and reduces the fitness of affected populations. Selective fishing mortality on heritable traits reduces the range of phenotypes for these traits within the exploited populations. This reduction in genetic diversity decreases populations' fitness, resistance and resilience to natural pressures and concomitant persistence, and can compromise the ability to evolve in response to environmental changes; and

- Broad cascading effects on ecosystem structure and processes manifested through food web links.

To meet a 'bycatch neutral' no net loss objective, residual adverse impacts that were not avoided and minimized may be offset by obtaining an equivalent gain, or a more-than-equivalent net gain could be obtained to meet a bycatch positive objective (Coralie et al. 2015; Maseyk et al. 2016; Booth et al. 2021). The offset could be delivered by having intervention actions implemented directly by the fishery. Or compensatory mitigation, including mitigation banking, a longstanding practice in wetlands management, (Environmental Law Institute 2006; Levrel et al. 2017) 
could be employed. Compensatory fisheries bycatch mitigation is a form of biodiversity offset where bycatch fishing mortality is mitigated through actions that address other conservation activities that, in theory, would not otherwise have been implemented (Wilcox and Donlan 2007; Squires and Garcia 2018). For example, a fishery could pay to support activities that mitigate bycatch in other fishing fleets, which could be either or both on-site and off-site, and either or both in-kind (mitigating bycatch of the same populations, age classes, sex ratio) and out-of-kind. A fishery could offset seabird bycatch by eradicating invasive rodents at a nesting colony (Wilcox and Donlan 2007; Pascoe et al. 2011). Or, a fishery could offset bycatch by paying for research activities, or fisheries monitoring and management activities. However, some definitions of offsets exclude many of these types of activities because they do not produce quantifiable biodiversity gains and may be subject to moral hazard on the part of the recipients (MilnerGulland et al. 2018).

Several sources of risk may prevent the success of offset activities. Problems with lack of performance, temporal lags in offsetting losses and lack of equivalency from off-site and out-of-kind mitigation could occur (Bull et al. 2013; Maseyk et al. 2016; MilnerGulland et al. 2018). An equivalent gain is not achieved when conservation activities do not achieve gains in populations affected by the fishery or if definitions of biodiversity units do not correctly account for the disparate population-level relative reproductive value of different age classes and sexes (Finkelstein et al. 2008; FAO 2010). The existence of a fisheries bycatch offset program might also cause regulators to deviate from strict sequencing. Furthermore, bycatch offset activities may not achieve equivalency because some manifestations of biodiversity are irreplaceable-they cannot be offset (Maseyk et al. 2016). For example, it may not be possible to offset intraspecific changes in genetic diversity from fisheries-induced evolution (Dunlop et al. 2009; Heino et al. 2015).

Evidence hierarchy with caveats

Table 2 defines a sequential evidence hierarchy (Jones and Steel 2018; Hayes et al. 2019; Luján and Todt 2021) that participants can use to categorize the retained publications and bycatch mitigation methods.
Decisions for regional fisheries bycatch management ideally should be based on evidence from metaanalytic modelling syntheses of accumulated research, which produce the most robust and generalizable findings, and from individual studies employing designs with the least risk of error and bias. Bycatch mitigation methods with evidence only available from studies with relatively weak forms of evidence, or lacking any evidence of efficacy, should only be considered as a precautionary approach when more certain alternatives to achieve a bycatch management objective are unavailable (e.g., weak hooks to increase cetacean escapement, Section S1).

Adapting the evidence hierarchies of the Oxford Centre for Evidence-Based Medicine (CEBM 2009; Stegenga 2014) and the Scottish Intercollegiate Guidelines Network Grading Review Group (2001), we integrated categories of meta-analytic synthesis studies and individual studies (Table 2). Quantitative meta-analytic synthesis studies based only on Randomized controlled trials and experiments (RCTs) is tier 1 , followed by individual RCT studies, considered the gold standard of individual studies, with the least risk of error and bias, as tier 2. Tier 3 is meta-syntheses of compiled publications that include quasi-experimental approaches (non-randomized, controlled studies), comparative experiment, or uncontrolled, observational studies, such as analyses of data from human observer and Electronic monitoring (EM) programs (Backmann 2017; Boesche 2020; Pynegar et al. 2021). Tier 4 is individual quasi-experiments and comparative experiments. Tier 5 is individual observational studies. Mechanistic studies, designed to answer questions about the physiological mechanisms causing a phenomenon (Marchionni and Reijula 2019), such as a behavioral response to a bycatch mitigation method, are in tier 6. Remaining tiers are all relatively weak forms of evidence. The qualitative synthesis approach of systematic literature review is tier 7, a higher-evidence ranking than qualitative unstructured literature review as tier 8. This is followed by individual expert surveys, which have a relatively high risk of bias and can have both low internal and external validity (Kahneman 2011; Hayes et al. 2019), as tier 9. Inconclusive records are combined with flawed studies, non-expert surveys, and bycatch mitigation method-species combinations with no evidence, to make up the lowest, most uncertain tier 10 of the evidence hierarchy (Table 2). 
Table 2 Evidence hierarchy of categories of methods for testing a hypothesis applied to assessing methods to mitigate the catch and mortality of vulnerable bycatch species. Rank order of 1 is least risk of error and bias, most generalizable and optimal for the basis of global and regional guidelines. Rank order of 10 is highest risk of error and bias, most contextspecific and least suitable for the basis for global and regional guidelines. $\mathrm{RCT}=$ randomized controlled trials and experiments

\begin{tabular}{lll}
\hline Rank & Method category Approaches and findings \\
order & Apto
\end{tabular}

order

$1 \quad$ Meta-analytic synthesis studies of RCTs

2 Individual RCTs

3 Meta-analytic synthesis studies that include quasiexperimental, comparative or observational studies

$4 \quad$ Individual quasi-experimental and comparative experimental studies

$5 \quad$ Individual observational studies

$6 \quad$ Mechanistic studies

$7 \quad$ Qualitative systematic synthesis

$8 \quad$ Qualitative unstructured synthesis

$9 \quad$ Expert survey

10 No records

Conflicting results

Non-expert surveys/opinion

Flawed studies
Meta-analytic studies of compiled RCT publications, including meta-analysis of the summary results from individual studies, mega-analysis of the original datasets used in individual studies, and data fusion using augmented or aggregated data-dependent priors with a significant overall (pooled) effect

Individual randomized controlled trials and experiments

Meta-analytic synthesis studies of compiled publications that include quasi-experimental (non-randomized, controlled) studies, comparative experimental studies, or observational studies

Individual quasi-experimental and comparative experimental studies

Individual observational studies

Individual studies designed to answer questions about physiological mechanisms causing a phenomenon, such as a behavioral response to a bycatch mitigation method or other treatment

Literature review following protocols for planning, implementing and reporting of the Reporting Standards for Systematic Evidence Syntheses (Haddaway et al. 2018), Collaboration for

Environmental Evidence (Pullin et al. 2020, 2021), and Preferred Reporting Items for Systematic reviews and Meta-Analyses (Page et al. 2021a,b)

Non-systematic literature review

Expert survey studies

Inconclusive - no records providing theoretical or empirical evidence, conflicting results for species-specific responses, nonexpert surveys, opinion (untested hypothesis) of a single organization or individual, and potentially flawed studies with low methodological quality
These evidence hierarchy categorizations should not, however, be used as an absolute interpretation of relative degree of risk of error and bias. Several strong arguments have been advanced against the wide spread in use of evidence hierarchies (Stegenga, 2014; Jones and Steel, 2018). A hierarchical approach also risks ignoring potentially important findings derived from studies using methods low on the evidence hierarchy. A network or plurality approach that integrates evidence across kinds of evidence might be a better approach (Bluhm 2005; Stegenga 2015).

For example, there is also no unequivocal basis for comparing the relative certainty between some categories-such as between a meta-analysis of compiled quasi-experimental studies and an individual RCT. Evidence hierarchies ignore potentially critical, context-specific features of evidence needed to test some hypotheses. The evidence hierarchy does not account for whether evidence of the response to an intervention is applicable to conditions in practice, such as under commercial fishing conditions, and has been externally validated (Stegenga 2014; Jones and Steel, 2018; Pullin et al. 2021). For bycatch mitigation methods whose efficacy is strongly affected by crew behavior, analyses of observer data may provide a more certain estimate of the size of catch or survival rate responses during commercial fishing operations than experiments (Gilman et al. 2005; Cox et al. 2007). While the evidence hierarchy does not account for this real- 
world efficacy, the database of compiled bycatch mitigation methods includes a data field that identifies whether the efficacy of a specific method is affected by crew behavior, described in the Literature Review section. For covariates or predictors that exhibit patterns, study designs with systematic treatment assignment and that are balanced may be preferrable to 'simple randomization' designs. By alternating the order of treatments in bycatch mitigation experiments, this allows the treatments to be exposed equally to varying, patchy conditions along the distribution of the fishing gear (Capello et al. 2013).

Furthermore, while global meta-analyses provide relatively robust evidence to inform global and regional policy, they may not be the most certain evidence for local-level decisions. By synthesizing estimates from a mixture of context-specific studies, the overall estimated effect from meta-analytic assessments, including meta-analyses, is relevant over diverse settings (Pfaller et al. 2018). Therefore, evidence from meta-analytic studies ideally should inform the development of global- and regional-level bycatch management strategies. However, because local and regional prevailing conditions may differ, bycatch mitigation measures that are effective at a global level may have a different response locally, for an individual fishery. For instance, the catch rate response to a change in gear design that affects size selectivity (e.g., gillnet mesh size and hook size) of an individual fishery that overlaps with a portion of the length frequency distribution of a population may differ from the response by a regional fishery that encounters the entire length frequency distribution.

In light of these arguments against using evidence hierarchies, participants should consider the evidence hierarchy categorizations as but one of various criteria to guide their design of a bycatch management strategy. Participants should account for all accumulated evidence for individual bycatch mitigation methods and the implications of different approaches for testing different hypotheses.

\section{Fishery-specific decision tool components}

Participation by all stakeholders

A stakeholder assessment may help determine which groups should participate in developing and implementing the bycatch management system. Stakeholders of capture fisheries may include:

- Local, national and regional government fisheries management authorities;

- Representatives from informal forms of self-governance and co-management frameworks implemented by small-scale fishing communities (Kolding et al. 2014; Karnad 2017);

- Companies in the seafood supply chain, which will vary in length and complexity by fishery, and can include the catch sector, fisheries associations, intermediaries, processors, exporters and importers, distributors, wholesalers, and end buyers including retailers and foodservice companies;

- Environmental and social non-governmental organizations; and

- Fisheries scientists.

The tool may be used by participants of fisheries improvement projects (FIPs) registered and tracked by FisheryProgress.org and members of client groups of fisheries certified against the Marine stewardship council (MSC) fisheries standard. In some fisheries, it may be relevant to expand this list to include indigenous peoples, gear suppliers, sports fishing associations, tourist industries and stakeholders of other commercial marine capture, aquaculture and ranching fisheries (Mikalsen and Jentoft 2001; Gudmundssen et al. 2006; CASS 2021).

Involving representatives of all interest groups from the outset of planning activities can create a sense of ownership and group norm, acceptance of the legitimacy of the management process, and concomitant motivation for compliance with the resulting management measures. It also enables incorporating a broad and diverse pool of expert knowledge, reduces conflict, and builds long-term trust and engaged participation (Mathur et al. 2008; Reed et al. 2009; Mackinson et al. 2011; Oyanedel et al. 2020). Most importantly, including all key groups at an early stage improves the likelihood of successful application of the decision tool and implementation of the bycatch management framework.

In some regions, retailers, foodservice and other major seafood buyers and their NGO partners are increasingly demanding that their seafood be procured from sustainable sources (Roheim et al. 2018). Ecological and social certification programs such as the MSC and Aquaculture Stewardship Council, FIPs, and 
other market-based mechanisms are increasingly being employed to both identify sustainable sources of seafood and to achieve gradual improvements in governance and fishing practices, including reducing problematic bycatch (Martin et al. 2012; Hall et al. 2017; Cannon et al. 2018; Osmundsen et al. 2020; MSC 2021). However, the relevancy of the scope of these initiatives, their suitability for small-scale, dataand management-deficient fisheries, and overall efficacy have been questioned (Roheim et al. 2018; Stoll et al. 2019; Tlusty et al. 2019). The sustainable sourcing requirements stated in public-facing policies and detailed in seafood product procurement specifications of major seafood buyers in the US, Europe and other markets have catalyzed seafood suppliers and the catch sector to participate in these certification programs and FIPs to maintain access to existing markets, obtain access to new ones and to obtain a price premium. In fisheries where market-based mechanisms are influential, this may result in interest by supply chain companies beyond the catch sector to directly participate in planning and implementing bycatch and other fishery improvement activities.

Review minimum data requirements, determine feasible risk assessment and mitigation approaches

The decision support tool is designed to be suitable for implementation by all global fisheries, whether datalimited or data-rich. But, application of the decision support tool requires, at a minimum, recent information on:

- The bycatch management framework, including monitoring, control, surveillance and enforcement systems;

- Catch rates to the species level or otherwise higher taxonomic grouping;

- Catch magnitudes to species level or otherwise higher taxonomic grouping; and

- Fishing methods, gear designs and vessel equipment that are potentially informative predictors of catch and mortality risk.

Fisheries lacking monitoring data on fishing methods and gear could apply rapid approaches, such as through a dockside inventory or expert assessment, in the first instance while building capacity for more robust monitoring. Ideally, stakeholders will have access to recent catch data, preferably obtained from conventional at-sea fisheries observer programs or EM systems. Otherwise, stakeholders can rely on less certain data from logbook and port sampling programs and expert surveys. Fisheries with limited or no data from human observer and EM systems could include activities in the bycatch management plan to address this deficit. A fishery lacking contemporary information on catch and effort, however, would first need to fill this information gap. Relying on catch data from other fisheries employing the same gear type is not advised as there can be substantial differences in catch between fisheries due to variability in susceptibility attributes and because this prevents robust performance assessments.

Logbook data self-reported by fishers are highly unreliable, in part, because fishers may have economic or regulatory disincentives to record accurate data, or may lack the time, training or interest (FAO 2002; Walsh et al, 2002; Mangi et al. 2016; Emery et al. 2019). Port sampling programs supply data only on landed catch. While port sampling data will provide information on most fish catch in fisheries where almost all fish are retained (e.g., Southeast Asian trawl fisheries and reduction fisheries), port sampling data in these fisheries will not include non-retained reptile, seabird and marine mammal bycatch (Suuronen et al., 2020). Expert surveys are a rapid and low-cost approach to provide an initial characterization of a fishery where previously little or no information was available. Information from fisher surveys may be the only data source available on fisheries of many developing countries. Data from expert surveys, however, are of relatively low certainty, especially in fisheries where vulnerable bycatch is highly sensitive due to the same issues with logbook data, but also due to retrospective bias (Tourangeau et al. 2000). Furthermore, there is a risk that the data collected from survey respondents are not generalizable and are unrepresentative of the underlying population that was sampled. This is a high risk if a probability sampling design is not employed and results in undercoverage bias (e.g., fishers of large-scale vessels and of vessels from certain seaports are not sampled), nonresponse bias is large and is not explicitly accounted for, there is a low response rate, and the questionnaire design or the way the questionnaire is administered causes biased responses (Choi and Pak 2005; Downes and Carlin 2020). 
Collecting a baseline, index-level of limited independent monitoring data from observers or an EM system can be used to validate fisher survey data and provide a more certain, though still rough, characterization of a fishery's catch composition. Long time series that span cyclical inter-annual and decadal climate cycles, trends in outcomes of climate change, variability in the temporal and spatial distribution of fishing effort, and that include data fields for potentially significant factors (e.g., vessel equipment and characteristics, fishing gear designs, fishing tactics and environmental parameters) that explain catchability, fishing mortality, and fishing power that are needed to standardize fishing effort are optimal (Hilborn and Walters 1992; Ward 2008; Cheung et al. 2010; Punt et al. 2014).

Thus, fisheries data from properly designed and managed observer and EM programs are much higher certainty and more complete than data derived from logbooks, port sampling and expert surveys. While EM systems are not yet able to collect all data fields of conventional observer programs, EM can provide more certain data, in both small- and large-scale fisheries (van Helmond et al. 2020), because it overcomes sources of statistical sampling bias faced by observer programs (Babcock et al. 2003; Benoit and Allard 2009):

- Observer effect: Fishers may alter fishing practices and gear when an observer or EM is present. Having vessels permanently outfitted with EM systems overcomes this source of bias, whether all or a random sample of EM imagery is analyzed;

- Observer displacement effect: Observers may not be placed on certain vessels for various reasons (undesirable conditions, too small, unsafe, mismatch in languages, and logistically challenging for placement and retrieval). Because vessel specification requirements for EM systems are much lower than for a human observer, EM avoids an observer displacement effect so that sampling is random and balanced proportionately across fleet components; and

- Coercion and corruption: Observers can be bribed or intimidated by fishers. This risk increases the more significant the consequences of the reporting. EM systems are not susceptible to coercion and corruption. EM data can also be independently verified, which is not possible with observer data.

Furthermore, observers can be deceived by crew, such as concealing bycatch for which a quota exists. This is still a risk with EM systems, but unlike observers, EM analysts can view multiple fields of view simultaneously, and EM systems can monitor continuously. EM systems can be used in a costeffective audit model, where all vessels have EM systems, and random samples of imagery and sensor data are reviewed to assess the precision of logbook data. To incentivize improved logbook data quality, penalties (e.g., full review of EM imagery, assign an observer, or issue a fine) can be assigned when a vessel is found to systematically record logbook data with low precision with EM data (Stanley et al. 2011; Emery et al. 2019).

Observer coverage rates remain at very low levels in most marine capture fisheries. For instance, 47 of 68 fisheries that catch marine resources managed by regional fisheries management organizations have no observer coverage (Gilman et al. 2014). To avoid statistical sampling bias, the necessary observer or EM coverage rate, as well as data fields and data collection methods, for a particular fishery depend on: (1) the objectives of analysis, including required levels of accuracy and precision of catch rates, and (2) aspects of each individual fishery-such as how many vessel classes exist, how many ports are used, the spatial and temporal distribution of effort, the frequency of occurrence of catch interactions for each species of interest, the amount of fishing effort, and the spatial and temporal distribution of catch (Hall 1999; FAO 2002; Babcock et al. 2003; Wakefield et al. 2018). In general, variability in precision and biases in bycatch estimates decrease rapidly as the observer coverage rate increases to about $20 \%$, assuming that the sample is balanced and there are no observer effects, and then decrease slowly towards 0 with $100 \%$ coverage (Hall 1999; Lennert-Cody 2001; Lawson 2006). At lower coverage rates, catch estimates will likely have large uncertainties for species with low capture rates (Amande et al. 2012), and may result in high uncertainty even for species that are more commonly caught if a small sample size is observed per stratum (e.g., by port, vessel category, and season) (Bravington et al. 2003). When low coverage rates result in small sample sizes, it is very likely that rare species 
susceptible to capture will not be identified. Species richness and other species-level biodiversity indices are extremely sensitive to sample size and species abundance distribution (evenness). The less even the relative abundance of species in a community is, the larger the proportion of relatively rarer species within that system will be detected with more sampling effort (Heck et al. 1975; Lawton et al. 1998).

In addition to these minimum information requirements, it would also be useful, but not a minimum requirement, to compile and assess available information on species-specific estimates of mortality rates for each observable component of total fishing mortality (ICES 2005; Gilman et al. 2013). These estimates would ideally be obtained both from the individual fishery and from a global gear-specific synthesis. Species-specific estimates of at-vessel and post-release mortality rates and information on fate of the catch (retained or discarded) enable stakeholders to identify the capacity of handling and release practices to reduce fishing mortalities. For nonretained species with relatively high at-vessel and post-release survival rates, handling-and-release practices could reduce fishing mortalities, in addition to catch avoidance and minimization methods. Conversely, for non-retained species with high at-vessel mortality rates, handling-and-release practices would have minimal capacity to reduce fishing mortality. This information also enables performance assessments of species-specific retention bans, including national Shark Sanctuaries that ban shark retention and shark finning restrictions, to determine if they are achieving objectives (Clarke et al. 2013; Tolotti et al. 2015; Gilman et al. 2016b; Ward-Paige 2017).

An evaluation of available data will inform whether qualitative, semi-quantitative or model-based quantitative ecological risk assessment approaches, described in the next step, can be employed. The data quality assessment will also determine which bycatch mitigation methods are feasible. For example, a rich time series of observer and EM data and robust surveillance system are required to support dynamic spatial management tools, while both data-limited and data-rich fisheries, as well as those with robust and limited surveillance programs, could implement static area-based management tools.
Select covered populations and benchmark contemporary ecological risks

Stakeholders determine which populations and stocks are within the scope of the bycatch management plan. These determinations are made easier by having explicitly defined thresholds above which impacts are deemed unacceptable. Some stocks may have defined limit and target reference points, which might be used to define a harvest control rule where interventions are triggered to keep the stock above the limit and fluctuating around the target (Punt, 2010). Similarly, limits of accepted impact have been defined for marine turtles based on monitoring annual changes in demographic parameters (Chaloupka et al. 2012). For some species, a fishery's legal and regulatory framework may define a bycatch threshold that triggers a management response. The United States Marine Mammal Protection Act, which is commonly used as an example, mandates an assessment of the magnitude of bycatch relative to biological reference points and the implementation of conservation actions if bycatch removals exceed a threshold. It uses a model known as Potential biological removal (PBR) that requires minimal demographic information to estimate mortality thresholds for marine mammal stocks (Wade 1998; Fader et al. 2021a). The PBR model has numerous adaptations, including for seabirds (Dillingham and Fletcher 2011) and marine turtles (Curtis et al. 2015; Casale and Heppell 2016), although issues have been raised over its application for these groups (Chaloupka and Musick 1997).

Bycatch quotas may be used to trigger a management response (Section S2). For instance, the Australian government has used fishery-specific seabird catch rate thresholds to measure performance and determine whether to require more rigorous bycatch mitigation methods, with a stated aim of achieving zero seabird bycatch (Australian Antarctic Division 2018). In contrast, Good et al. (2020) found that all 12 countries with a National Plan of Action for Reducing Incidental Catch of Seabirds employed qualitative judgement for at least one fishery to determine whether seabird bycatch was problematic, and only three countries employed quantitative, model-based population assessments to make the determination. However, $19 \%$ of the seabird National Plans included explicit thresholds that would trigger a bycatch 
management response, such as Australia's catch rate threshold (Good et al. 2020).

The MSC's Fisheries Standard includes a criterion to avoid and minimize injury and mortality of Endangered, threatened and protected (ETP) species that assesses whether a fishery: (1) meets national and international requirements for the protection of the ETP species, and (2) does not hinder the ETP species' recovery (MSC 2018). For ETP species with no national or international limits that trigger a management response, MSC does not provide explicit, quantitative cutoffs for when a fishery hinders recovery or causes unacceptable impacts (MSC 2018). Instead, to determine whether ETP bycatch mitigation actions are required, assessors consider whether direct fishery removals, which includes post-release, ghost fishing and other unobserved mortalities, are "highly likely to not hinder recovery", which takes into account the fishery's bycatch levels and information on population status and biological reference points, if available. Assessors also consider whether indirect fishery effects, such as reduced prey availability, "are highly likely to not create unacceptable impacts," (MSC 2018). Thus, like most seabird national plans of action, MSC's fisheries standard lacks an explicit threshold for unacceptable impacts from bycatch of ETP species.

International bodies also tend not to define explicit thresholds but instead offer qualitative guidelines. For instance, while recommending that States with longline fisheries conduct assessments to "determine if a problem exists," and stating that the criteria used to determine what constitutes a problem and whether a national plan of action on seabird bycatch is needed should be explicitly defined, the Food and agriculture organization of the United Nations' (FAO's) International Plan of Action for Reducing Seabird Capture in Longline Fisheries and supplement do not define thresholds for seabird bycatch impacts that warrant interventions (FAO 1999, 2009). Bycatch management measures of regional fisheries management organizations tend to similarly lack explicit thresholds (Gilman et al. 2014). However, there are exceptions, such as a WCPFC marine turtle bycatch rate threshold for shallow-set swordfish longline fisheries (WCPFC 2009, 2018a), discussed in Section S3.2.

For each vulnerable species susceptible to capture in a fishery, stakeholders need to review national and international measures to determine if thresholds for unacceptable impacts are defined. For species lacking thresholds, stakeholders will need to agree on an approach to determine the scope of their bycatch management program. Findings from Ecological risk assessments (ERAs) that estimate relative or absolute impacts are helpful to both fisheries with and without defined thresholds for unacceptable bycatch impacts. Stakeholders compile and synthesize available fisheries-dependent data and relevant publications to identify vulnerable species that are susceptible to capture in the fishery. The assessment will also benchmark relative and absolute risks, such as by compiling and synthesizing findings from recent Productivity-susceptibility analyses (PSAs) and other semi-quantitative assessments of relative risks, stock assessments and population models, and possibly broader multispecies models (Gilman et al. 2017). For fisheries lacking ERAs, or with ERAs with limited scopes or that are dated, stakeholders may decide to conduct new or update past ERAs in order to inform their decisions on the scope of the bycatch management program.

ERAs evaluate the magnitudes and likelihood of adverse ecological consequences of anthropogenic and natural stressors (Norton et al. 1992). Methods for ERAs of the effects of fishing have been developed, fairly recently, for the continuum of data-poor to datarich fisheries. ERA methods include rapid, first order, qualitative evaluations, semi-quantitative assessments, and model-based quantitative assessments (Hobday et al. 2011). Qualitative ERAs are typically based on expert opinion. For example, the Australian government and MSC use the qualitative method 'Scale, Intensity, Consequence' analysis. The approach employs expert judgment to identify the worst plausible scenarios for impacts of a fishery, determine the degree of spatial and temporal overlap between a stock or habitat and fishing effort, estimate the degree of intensity of fishing activities that adversely impact the stocks or habitat and ecosystem integrity, and identify the consequences of fishing on population viability, habitat integrity and ecosystem integrity (Hobday et al. 2011; MSC 2020).

The objectives of analysis of most semi-quantitative fisheries ERAs have been to determine population- and species-level relative risks from fishing mortality of individual taxonomic groups of conservation concern, most employing PSAs (e.g., Stobutzki et al. 2002). PSAs assess productivity through use of 
attributes for intrinsic factors, such as demographic characteristics of a population, stock or species. These productivity attributes provide an indicator of relative resistance to fishing mortality and resilience or ability to recover from depletion. Susceptibility considers extrinsic factors that influence catch and mortality risk, such as areal overlap, encounterability, selectivity and survival rate (Hobday et al. 2011). A new ERA approach that estimates instantaneous fishing mortality to compare to reference points of yield-per-recruit models employs many of the same attribute values as conventional PSAs (Ecological Assessment of the Sustainable Impacts of Fisheries or EASI-Fish, Griffiths et al. 2019). Instead of employing arbitrary reference points for productivity and susceptibility to assess relative risk as employed in PSAs, EASI-Fish employs commonly used reference points that are intended to be comparable across all assessed stocks and populations, so that findings identify a fishery's effect on biomass yield across species groups with variable life histories (Griffiths et al. 2019). PSAs and other semi-quantitative ERAs of the effects of fisheries bycatch that are suitable for data-poor settings can rapidly identify highest-risk biodiversity units (populations, stocks, species, groups of species, habitats) so that precautionary management responses can be quickly implemented (Hobday et al. 2011). Findings from PSAs and other semi-quantitative ERAs provide a first order basis for determining the focus of a bycatch management strategy, where populations identified as being most vulnerable could be prioritized for more robust quantitative modeling.

The objectives of analysis of model-based quantitative methods for ERAs of the effects of fishing include to assess absolute risk, e.g., of population extirpation, irreparable harm to a stock, habitat loss, and loss in genetic diversity (Hobday et al. 2011). Conventional single stock assessment methods are the most common form of a quantitative ERA, used to assess the status and temporal changes in stock status and predict stock responses to different management options (Hilborn and Walters 1992). They are typically used for principal market species but more recently have also been used for stocks of sharks and other incidentally caught species of conservation concern, including through new approaches designed for data-poor stocks (e.g., Fu et al. 2016). Numerous analytical approaches have been used in quantitative ERAs of the effects of fishing to define threshold population sizes and fishing mortality rates beyond which populations are at risk of irreparable harm or extirpation, with a range of data requirements and concomitant range in certainty in outcomes (Wade 1998; Chaloupka 2003; Lewison and Crowder 2003; Dulvy et al. 2004).

In determining which species to include in the bycatch management framework, stakeholders need to also consider whether a species is targeted, incidental catch that has market value and the proportion of the catch of that species that is retained, versus nonmarketable catch that is not retained. While robust, comprehensive harvest strategies can be developed for all species, including principal market species and non-retained vulnerable bycatch species, it is reasonable to expect strong resistance from the catch sector and other supply chain companies against proposals to apply mitigation measures to principal market species. Therefore, stakeholders may decide not to include species of sharks or other relatively vulnerable species in a bycatch mitigation framework if they are primarily retained and critical to the fishery's economic viability, especially if harvest strategies are in place for these species.

\section{Benchmark contemporary fishing practices}

Next, participants compile available information on contemporary fishing vessel equipment, fishing methods and gear designs that are potentially informative predictors of catch and survival rates of vulnerable bycatch species. This is implemented systematically by using the compiled exhaustive database of bycatch mitigation methods (Tables S1 and 1). Each alternative bycatch mitigation method informs what information needs to be compiled. In addition, stakeholders review publications, including stock assessments and studies analyzing observer data with effort standardized using empirically-based statistical models, to compile explanatory variables that affect fishing efficiency and may significantly explain catch and fishing mortality rates of vulnerable species (Maunder and Punt 2004; Gilman et al. 2017).

For example, information on anchored gillnet designs, such as the profile and whether tiedowns are employed, is needed to determine whether modifications are feasible to mitigate marine turtle bycatch (FAO, 2010, 2016). Similarly, information on contemporary longline hook shape, hook minimum width 
and wire diameter are needed to assess the potential for changes in these gear components to mitigate catch and mortality rates (Tables S1, 1). Some vessel equipment can also significantly affect the catch risk of individual vulnerable taxa. Various technology aids for fish finding and gear deployment and retrieval can affect effective fishing power (Palomares and Pauly 2019). To understand the potential capacity of areabased management tools to mitigate species-specific bycatch in a fishery, information on the recent spatial and temporal distribution of bycatch and target catch rates and of fishing effort is needed. This information will be used in subsequent steps to help stakeholders define the bycatch management framework. For example, if stakeholders adopt objectives and milestones to reduce marine turtle catch risk, then knowledge of contemporary hook types and whether spatially and temporally predictable turtle bycatch hotspots occur supports stakeholders to define actions that achieve their objective and milestones.

Benchmark the contemporary bycatch management framework

Participants also characterize the contemporary bycatch management framework. This includes the monitoring system, bycatch management measures, surveillance and enforcement systems, and the legal and regulatory frameworks. Voluntary industry measures are also reviewed. Findings and recommendations from any performance assessments of fisheries management systems in general and of bycatch management in particular should be reviewed.

Benchmarking the bycatch governance system enables stakeholders to determine the suitability of alternative mitigation measures for compliance monitoring. For example, gillnet mesh size restrictions may be effectively monitored through dockside inspections, but requirements to use pingers or lightsticks, or that restrict tiedown designs require at-sea monitoring. An assessment of the management and industry frameworks also enables determining if incentives are adequate to incentivize compliance. Compliance with bycatch mitigation measures can be incentivized through a broad range of combinations of penalties and rewards, including as a consequence of reaching a bycatch quota (Section S2). Negative economic, market-based and reputational incentives include: closure of part or all of fishing grounds, required use of bycatch mitigation measures or more stringent methods, purchase of bycatch quota (under individual transferable bycatch quota programs, a market for bycatch quota is created, where more skilled fishers sell unused quota to less capable vessels, Section S2), levy (tax) assessed per defined bycatch unit, reduced or withheld subsidies, higher permit or license fee, higher tax rate, reduced quota for target species, not achieving or losing certification against an ecological fisheries sustainability standard, lower Fishery improvement project (FIP) ranking, and negative media coverage. Reward-based measures include the converse of these penalties, such as the sale of unused bycatch quota, provision of a subsidy or increased subsidy, etc. (Gjertsen et al. 2010; Pascoe et al. 2010; Booth et al., 2021; Squires et al., 2021).

Findings from a performance assessment of bycatch management measures may help determine improvement priorities. For instance, performance assessments may identify whether modifications to a prescribed measure could improve bycatch mitigation efficacy (e.g., the required minimum width of 'wide' hooks is too narrow to reduce hardshelled turtle ingestion) and whether changes in gear designs could improve crew safety (e.g., the risk from flybacks of branchline weights could be reduced by changing from conventional weights that are crimped in place to sliding weights). Performance assessment findings could identify whether any discrepancies in performance of a mitigation method between experiments and commercial use (Cox et al. 2007; Gilman et al. $2005,2017)$ are due to crew behavior that could then be addressed through more explicit requirements on implementation in combination with more robust compliance monitoring (e.g., crew do not maintain streamer tori lines over baited hooks). If a recent performance assessment of the fisheries management framework documents systematic noncompliance due to, for example, enforcement actions not consistently being taken for identified infractions, or penalties that are too lenient, then this highlights an improvement action to include in the bycatch management strategy, and also informs which bycatch mitigation methods are currently suitable. 
Develop and adopt goals, SMART objectives and performance standards

Stakeholders define overarching goals, and explicit objectives and performance standards to achieve the goals, for the bycatch management framework. This is guided by information from previous steps on contemporary bycatch relative risks, the identification of which populations and stocks are within the scope of the bycatch framework, and contemporary fishing practices and management system. The overarching goals should define whether residual bycatch removals will be offset to achieve no net loss or a net gain (Booth et al. 2020), the economic cost-effectiveness of bycatch mitigation interventions (Squires and Garcia 2018), and the balance between practicality and safety costs and conservation gains.

Bycatch management objectives should be specific, measurable, achievable, relevant and time-oriented (SMART), developed following a process that is suitable to the fishery-specific context (Chen 2015; Bjerke and Renger 2017). There are numerous participatory decision tools available to assist stakeholders with balancing competing objectives of managing vulnerable bycatch, where different interest groups place disparate importance on economic, social and ecological objectives (i.e., the triple-bottom-line, Elkington 1994; Halpern et al. 2013; Abbott et al. 2014). For example, conjoint analysis and choicebased survey approaches, used predominantly in marketing and business, assess consumer preferences between alternative products, services or features and force respondents to rank alternative attributes by making trade-offs between them (Green et al. 2001). These approaches have been employed in fisheries applications to understand fisher behavior and to weight objectives (Wattage et al. 2005; Shepperson et al. 2016). Multi-Criterion Decision Analysis is a similar approach that has been used to rank alternative bycatch policy interventions (Huang et al. 2011; Lebon and Kelly 2019).

Participatory tools can assist stakeholders to reach agreement on various tradeoffs that might be necessary in designing the bycatch management system. As harvest control rules for stocks of principal market species include target reference points that can be based on achieving an agreed balance of biological and socioeconomic objectives while staying safely above a biological limit reference point (Rayns 2007;
Skirtun et al. 2019), so too should bycatch management frameworks. To attain acceptable tradeoffs between institutional, socioeconomic, biological and broad ecosystem objectives, management measures can be designed to achieve Pretty Good Yields for single and multiple stocks (Hilborn 2010; Rindorf et al. 2017).

The scope of the bycatch management objectives covers:

1. Catch and fishing mortality levels or rates for vulnerable bycatch species;

2. Acceptable tradeoffs from multispecies conflicts;

3. Acceptable costs to commercial viability (practicality, economic viability, crew safety); and

4. Requisite improvements in legal and regulatory frameworks to enable components of a robust bycatch management framework; in monitoring and surveillance systems to enable adequate compliance monitoring and performance assessments; and in the enforcement framework to ensure it adequately incentivizes compliance.

For each objective, stakeholders define performance standards or milestones that support achieving the objective. For example, an individual fishery might adopt an objective of capping fleetwide leatherback turtle catch levels to a maximum of 16 per year within 5 years, while a regional fishery might have an objective of recovering a depleted stock so that it is above a biological limit reference point within 5 years, and within 10 years is fluctuating around a target reference point. Milestones for this former objective could be to gradually reduce annual leatherback turtle catch levels with a year 1 milestone of 25 , year 2 of 20, etc., and to have the fleet change to using only circle hooks and fish bait by the end of year 2 . Objectives on acceptable multispecies conflicts might specify, for example, a cap of an increase in pelagic shark catch rates of $15 \%$ resulting from the circle hook requirement (Reinhardt et al. 2018), but offset slightly due to the bait requirement (Gilman et al. 2020), where annual milestones for this objective would track changes in leatherback and shark captures. To be achievable, objectives and milestones must account for the capabilities of the fisheries management system, including data quality. A data-limited fishery with minimal or no observer and EM coverage might initially be restricted to adopting primarily process objectives, such as to have all vessels in a pot fishery 
install marine mammal excluder devices by a specified date, and not outcome-based objectives, such as reduced marine mammal bycatch rates or fleetwide levels.

For regional fisheries and for stocks and populations that have undergone assessments with conclusive findings, objectives would specify an annual bycatch fishing mortality level predicted to recover a depleted population, or predicted to maintain a sustainable absolute population size or stock biomass, or achieve sustainable anthropogenic mortality or population growth rate. An objective defining a threshold fishing mortality magnitude could include activities that (1) avoid or reduce catchability, by reducing effort and/or reducing bycatch rates, and (2) avoid, minimize or offset one or more component of total fishing mortality (defined in the section "Sequential Bycatch Mitigation Hierarchy"). For individual fisheries where contributions to cumulative anthropogenic mortality of stocks and populations are nominal, stakeholders may still define an objective based on a change in bycatch and mortality levels, or could define the objective based on changes in bycatch rates and at-vessel, at-release and post-release mortality rates. For the latter, indicators of probability of post-release survival could be employed. However, for individual fisheries with mortality levels that do significantly impact population viability, objectives based on bycatch rates will be ineffective if they do not account for the effect of changes in other variables that affect fishing mortality levels and for changes in population status (Tuck 2011).

Stakeholders define acceptable impacts on economic viability, such as what reduction in catch rates of marketable species and in fishing effort are acceptable (Arlidge et al. 2020). Evaluating the effect of different bycatch measures on the bycatch/target catch ratio enables assessing tradeoffs between bycatch minimization and target catch optimization objectives (Hall 1996). What is considered an acceptable effect of bycatch measures on economic viability will vary substantially between fisheries. In general, small-scale fisheries may have no economic surplus to accommodate increased economic costs. For these fisheries, if the catch sector is expected to cover costs for bycatch mitigation activities, then this will constrain options. If other stakeholders are to cover initial and ongoing increases in economic costs, then a wider range of options becomes feasible. In particular for economically marginal fisheries, it will be important to identify maximum bycatch reduction for minimum cost (Hall 1996; Squires and Garcia 2018).

Objectives on acceptable reductions in practicality and fisher safety could use rankings that stakeholders will assign in a subsequent step to define objectives on individual and cumulative effects of mitigation methods that would be employed simultaneously. For example, stakeholders may define an objective for the bycatch management framework to not create more than a medium cost in practicality for fishers' implementation.

Stakeholders identify any improvements in monitoring, surveillance and enforcement systems, and in the legal and regulatory frameworks, that they anticipate being required to meet objectives. For example, if an objective defines a catch level for a rare-event bycatch species, there may be a need to increase the observer or EM coverage rate to enable robust fleetwide raised estimates. Like links in a chain, robust control measures on bycatch alone will be ineffective if any other links of the bycatch management framework are weak. The existing legal and regulatory frameworks may define explicit objectives for bycatch management of some species, providing a starting point for development of a comprehensive suite of bycatch management objectives. However, globally, most national and regional fisheries lack explicit bycatch objectives (Gilman et al. 2014; Davidson et al. 2015; Good et al. 2020).

In a subsequent step of the decision process, stakeholders use these objectives and performance standards to develop a bycatch management framework, which will define explicit actions, milestones or outcomes resulting from the action, a schedule for implementing the actions and achieving each milestone, who is responsible to implement each activity, a budget and source of funding. These explicit objectives, milestones and schedule support periodic performance assessments, where findings will be used to adapt the management framework, which is described in the final step of the decision tool.

Select a subset of the comprehensive suite of bycatch mitigation measures

Based on the assessment of vulnerable bycatch species, the contemporary fishing practices and management system, and agreed objectives, stakeholders 
create a short-list of the exhaustive suite of bycatch mitigation measures that are of relevance to the fishery. The bycatch mitigation methods that are currently in use, either due to voluntary industry practices or the contemporary fisheries management framework, identified when benchmarking contemporary fishing practices and bycatch management framework, would be included in this subset.

Participants may agree to exclude certain bycatch mitigation methods because one or more stakeholder group strongly objects to its inclusion, where other options with broader support are available to meet objectives. Bycatch mitigation methods for a taxonomic group that is not susceptible to capture in the fishery would be excluded. For instance, if a fishery occurs in an area where there is no risk of seabird capture (e.g., the species susceptible to capture in that gear type do not have distributions that spatially overlap with the fishing grounds), then stakeholders would exclude methods to mitigate seabird bycatch. Some mitigation methods may be excluded that require monitoring and surveillance approaches for robust compliance monitoring that are not perceived as being feasible to meet within the time frame adopted for achieving the objectives. Bycatch mitigation methods that pose a risk of injuring vulnerable bycatch species (e.g., fish and vegetable oil slicks, lasers and acoustic harassment devices, Morandin and O'Hara 2014; ACAP 2019; Tixier et al. 2021) should be excluded.

Participants may also decide to exclude methods that do not meet a threshold level of evidence of bycatch mitigation efficacy, such as the effects of acoustic-harassment devices and pyrotechnics on cetacean depredation and bycatch rates (Tixier et al. 2021) and effects of weak hooks on escapement rates (Section S1). Conversely, despite having a low evidence hierarchy tier, participants may decide to retain a mitigation method as a precautionary measure if more certain approaches are unavailable.

\section{Rank bycatch mitigation methods}

Stakeholders rank the shortlisted bycatch mitigation measures. In conducting the ranking, stakeholders should recognize that certain combinations of mitigation methods may be optimal to meet objectives, and account for the interacting effects of some variables, discussed in the Literature Review section. Stakeholders will also consider measures' categorizations in the mitigation and evidence hierarchies. However, participants are not restricted to following the sequential hierarchies because, in addition to best overall conservation outcomes, resource management decision-making is also guided by social, economic and governance considerations (Bianchi and Skjoldal 2008; Morgan 2012; Squires and Garcia 2018; Booth et al. 2020). Therefore, within and across each of the hierarchy tiers, stakeholders rank mitigation methods according to:

(1) How they contribute to meeting objectives for mitigating catch and mortality rates of vulnerable bycatch species;

(2) Whether they meet objectives on acceptable costs from cross-taxa conflicts;

(3) Whether they meet objectives on acceptable costs to practicality, safety and economic viability; and

(4) Enforceability of the method given the capacity of the fisheries management system to conduct compliance monitoring and the effect of crew behavior on performance of the method.

For fisheries with limited monitoring and surveillance capacity, bycatch mitigation methods whose performance is strongly affected by crew behavior (e.g., blue-dyed bait and tori lines) will be ranked low against the compliance monitoring criterion. Methods that do not rely on crew behavior during fishing, such as methods for which compliance can be determined through dockside inspection (e.g., hook type, branchline weighting design and leader material), will be ranked high, while methods that are affected by crew behavior but can be confirmed without observers and EM (e.g., static area-based management tools input controls on number and time-of-day of fishing operations can be monitored with a satellite-based vessel monitoring system) will be ranked as intermediate.

Whether a fishery is artisanal, with small-scale vessels, or industrial, will affect the rankings of bycatch mitigation methods against criteria for economic viability, practicality and other attributes. For example, small longline vessels might have limited deck space to accommodate underwater setting devices. Radio buoys, used to track the location of longline gear while drifting, help avoid gear loss, reducing the risk of ghost fishing and other adverse ecological and socioeconomic effects of ALDFG, are 
commonly used in larger-scale longline fisheries but might be cost-prohibitive and impractical for use by small longline vessels with limited deck space for storage.

Section S4 presents an example of an expert survey approach that was used to rank seabird bycatch mitigation methods for relative practicality, safety and economic viability, which could be expanded for integrated, multi-taxa planning. A narrative synthesis from a literature review that compiles available information on the commercial viability criteria for each mitigation method, such as presented in Table 1 and Table S1, would support experts in completing the survey. Results of the expert survey could then be used to evaluate whether alternative bycatch management frameworks meet objectives.

There is limited or no quantitative information available for most bycatch mitigation methods on their practicality, safety and economic costs. Furthermore, for some bycatch mitigation methods, assessments against these criteria will be highly variable by individual fishery. Therefore, for these criteria, the decision support tool does not establish sequential hierarchies. For example, the effect of a change in hook minimum width on economic viability would depend on: variability in the length frequency distribution of a species that overlaps with a fishery, the difference between the widths of the conventional and new hook, and the difference in the hook widths relative to the species' range of mouth sizes. Similarly, outcomes of assessments of the relative efficacy at meeting objectives on enforceability will vary substantially by individual fishery. The decision support tool therefore assesses mitigation methods against these criteria according to fishery-specific conditions. Table S1 provides a narrative synthesis and Table 1 a simplified assessment of economic viability, practicality, safety and compliance monitoring to support this fishery-specific assessment process.

\section{Conduct bycatch management strategy evaluation}

Management strategy evaluation (MSE) is conventionally used to evaluate the likely performance and tradeoffs of alternative management strategies, including fisheries harvest control rules, against operational objectives, and to explore the effects of uncertainty, for individual stocks, and more recently for multispecies and ecosystem-level evaluations (Sainsbury et al. 2000; Smith et al. 2007; Fulton et al. 2014; Punt et al. 2016; Perryman et al. 2021). MSE has also recently been applied to simulate effects of alternative fisheries bycatch management measures to assess their predicted efficacy against explicit performance standards. Some MSE approaches have been applied to individual fisheries and used expert opinion and stakeholder consultation (Arlidge et al. 2020; Booth et al. 2020) and quantitative, model-based approaches (Tuck 2011; Smith et al. 2021). Others have been applied to regional fisheries using model-based approaches (Harley et al. 2015; Harley and Pilling 2016). The narrow scope of some of these MSE assessments (e.g., the scope of the regional studies was to assess the effect of alternative combinations of bycatch mitigation interventions on catch and mortality risk of selected epipelagic sharks; Harley et al. 2015; Harley and Pilling 2016) theoretically, given the availability of data inputs, could be expanded to assess a broader range of mitigation methods, multiple taxa, and other objectives (commercial viability, multispecies conflicts). Model-based MSE approaches includes operating models of the biological components of the system and of the fishery, estimates of the uncertainty of each of the terms of the operating models, and an implementation model of the application of the fisheries management framework (Punt et al. 2016).

The assigned categorical ranks, discussed in the previous section, in combination with the information contained in the database of compiled bycatch mitigation methods (Tables 1, S1) are used as inputs for MSE. MSE can be used to predict whether an alternative bycatch management strategy is likely to meet the stakeholders' agreed objectives on desired changes in catch and mortality rates of vulnerable bycatch, acceptable multispecies conflicts, and objectives related to acceptable reductions in practicality, economic viability and crew safety - so that alternative frameworks that do not meet all objectives can be eliminated. For the bycatch management frameworks that do meet all objectives, the results of the MSE would also identify the tradeoffs amongst the objectives of each alternative bycatch management framework, information then used by stakeholders to select the framework with the most preferable tradeoffs. 
Adopt and implement bycatch management framework

Next, stakeholders develop and adopt a bycatch management workplan that identifies their agreed objectives and selected bycatch mitigation measures that was simulated by bycatch management strategy evaluation to meet their objectives. During this stage, stakeholders will also identify additional agreed improvements to other components of the fisheries management framework of relevance to achieving bycatch-related objectives. This may include improvements to fisheries monitoring, surveillance and enforcement; amendments to legal and regulatory frameworks, including new and amended management measures under domestic and regional fishery bodies; and voluntary industry measures (catch sector company policies, industry code of practice, buyer seafood sourcing policies and product specs).

The mechanisms for documenting and implementing the bycatch management plan will vary depending on the fishery-specific context. This could include a client action plan for meeting conditions of certification against the MSC fisheries standard, actions in a FIP workplan, government publication, or a voluntary industry report.

Regardless of the mechanisms for documenting the plan and implementation, a bycatch management workplan should include explicitly defined activities, milestones and a schedule for implementation. The workplan should also identify who is responsible for implementing each activity, a budget and source of funding, and how each activity and milestones will contribute to achieving an objective of the bycatch management program (e.g., template FIP workplan, FishChoice 2021). The workplan should also have a tactical component that details the process for implementing the actions (Die 2002). Discussed previously, the workplan should document the process for independent performance assessments (Die 2002), which might be made public and contain evidence of progress, such as is required for independent audits of FIPs and for annual surveillance audits of MSC certified fisheries (MSC 2020; FishChoice 2021). Stakeholders then initiate implementing the actions.

When considering the multitude of options for the structure of a bycatch management framework, stakeholders might consider how the design can incentivize the fishing industry to meet performance standards and participate in research to fill priority knowledge gaps and innovate new, more effective and commercially viable bycatch mitigation methods. Adopting individual bycatch quotas without prescribing mitigation methods would incentivize fishers' innovation of bycatch mitigation approaches, including by participating in cooperative research (however, see Section S2 for a discussion of criteria necessary for effective bycatch quota frameworks). For bycatch mitigation methods ranked low on the evidence hierarchy, more primary research is needed to enable robust meta-analytic synthesis research. For example, additional studies with large sample sizes are needed to assess the efficacy and economic viability of moveon rules to minimize bycatch of vulnerable species, which could be integrated with fleet communication and bycatch limit measures. This is a priority in particular for mitigating longline-cetacean depredation and bycatch, to improve the limited understanding of the factors that determine thresholds for distances moved and duration between sets to reduce interaction rates (e.g., the local abundance of cetaceans within fishing grounds; behavioral differences between cetacean species, populations and between individuals within a population; fishing vessel density; catch composition; individual vessel practices), the magnitude of reduced risk, and the associated economic and practicality costs (Fader et al. 2021b; Tixier et al. 2021). Similarly, more evidence is required on longline bait type effects on seabird and cetacean bycatch risk (Gilman et al. 2020) and on which fishing hook variables significantly explain cetacean catch and mortality risk (Section $\mathrm{S} 1$ ).

The approach for seabird bycatch management of the South Pacific RFMO provides a useful example of a framework that may incentivize fishers to minimize seabird bycatch: Trawl fisheries with $100 \%$ observer coverage and a seabird mortality rate below a threshold ( $<1$ seabird mortality per vessel per year) for five consecutive years is exempted from employing mitigation methods (SPRFMO 2017). Similarly, tuna RFMOs and some national fisheries management authorities employ a menu approach, allowing for selecting alternative combinations of seabird bycatch mitigation methods from a suite of options (e.g., WCPFC 2018b). If used in combination with explicit fleet- or vessel-based bycatch quotas or similar performance standards and adequate monitoring, this approach might incentivize fishers to select optimal 
mitigation approaches and achieve high compliance. Given the rudimentary state of most fisheries management systems, bottom-up approaches that foster industry ownership and a group norm for implementation of effective bycatch mitigation methods might achieve higher compliance and enable tapping fishers' knowledge and skills to develop new, effective and commercially viable bycatch mitigation methods (Gilman et al. 2005; Hall et al. 2007; Oyanedel et al. 2020).

\section{Adaptive management}

In the final step of the decision tool, stakeholders periodically adapt the bycatch management plan and bycatch management framework (Die 2002; MilnerGulland et al. 2018; Booth et al. 2020). Stakeholders continuously monitor the bycatch management framework by conducting regularly-scheduled, impartial (third or otherwise second-party) performance assessments to determine whether the system is achieving objectives and scheduled milestones and adapt the bycatch management framework as needed. Amendments may also be warranted when there are changes in fishing practices (gear design, fishing methods); changes in bycatch rates, levels and composition, including changes to sex ratios and age classes of vulnerable bycatch; new information from monitoring programs; and results from updated or new ecological risk assessments. Modifications may also be warranted based on improved evidence from primary and synthesis research, and when new bycatch mitigation methods become available. Amendments may be required if stakeholders change their overarching objectives. RFMOs' adoption of new or amended measures and new or amended Client Action Plans to address conditions of certification against MSC's fisheries standard may also trigger updates to the bycatch management plan.

Depending on the amendments made to the bycatch management plan, fisheries management authorities might adopt or amend the legal and regulatory framework and modify fishing license agreements. Stakeholders might adopt new actions to improve the fisheries management framework, including monitoring, surveillance and enforcement programs. Amendments to the bycatch management plan may require industry participants to adopt or adapt fishing company policies, industry codes of practice, sustainable seafood sourcing policies and product specs.

\section{Conclusions}

The proposed decision support tool for integrated bycatch management can enable fisheries stakeholders to identify a subset of an exhaustive database of bycatch mitigation methods that meet their agreed SMART objectives and are suitable given their fisheries management framework's capacity for monitoring, surveillance and enforcement. Employing accepted approaches for systematic literature reviews to compile gear-specific, exhaustive databases of bycatch mitigation methods improves upon unstructured approaches, which are not replicable, and risk introducing prevailing paradigm, familiarity, citation and publication biases and concomitant biased conclusions (Sutton 2009; CEE 2013; Bayliss and Beyer 2015). SMART objectives address expectations for rates and levels of catch and mortality of vulnerable bycatch species, acceptable tradeoffs from multispecies conflicts that are unavoidable, and tradeoffs in costs related to economic viability, practicality and fisher safety. By explicitly accounting for multispecies conflicts resulting from the implementation of some bycatch mitigation methods, the tool improves upon prevailing piecemeal systems for bycatch management (Clarke et al. 2014; Gilman et al. 2019a). Categorizing mitigation methods within tiers of sequential mitigation and evidence hierarchies allows the decision-making process to account for the relative biodiversity conservation performance and relative certainty of evidence of alternative approaches, respectively.

Pilots of the framework are needed in priority gear types with most problematic vulnerable bycatch, including artisanal and industrial pelagic and demersal longline, set and drift gillnet, trawl, seine and trap fisheries (Gray and Kennelly 2018). Pilots are also needed in fisheries with a variety of levels of data quality and technical and management capacity. The steps and outputs resulting from implementation of the support tool are summarized in Table 3. Pilots of the decision support tool are an important initial step to identify any critical gaps in the proposed process, determine whether the tool's outputs are adequate for guiding the decision-making process, and learn how 
Table 3 Summary of steps and outputs from implementing the decision support tool for integrated bycatch management

Decision tool step Output

\section{Gear-specific Preparation}

Systematic and unstructured literature reviews

Sequential mitigation hierarchy

Sequential evidence hierarchy

-Systematic review protocol

-Flow diagram of the literature view process and results

-Database of retained results

-Comprehensive database of bycatch mitigation method records (template in Table S1)

-Simplified database of a sample of bycatch mitigation method records with quantitative evidence of efficacy or that are in commercial use (template in Table 1)

-Detailed narrative syntheses of prioritized bycatch mitigation methods (optional)

-Bycatch mitigation methods categorized into mitigation hierarchy tiers

-Bycatch mitigation methods categorized into evidence hierarchy tiers (Table 2)

\section{Fishery-specific Planning and Implementation}

Stakeholder assessment

Evaluation of available data and information

Identification of species requiring mitigation interventions and benchmark of contemporary ecological risks

Benchmark of contemporary fishing practices

Benchmark of the contemporary bycatch management framework

Adoption of goals, objectives and performance standards
-Identification and direct involvement of relevant participants in planning and implementing the bycatch management framework, and identification of incentives for bycatch improvements by stakeholder

-Identification of data quality deficits and plan to address deficits. Identification of feasible approaches for bycatch ecological risk assessment and mitigation methods

-Identification of relative and absolute risks of populations and stocks susceptible to capture, and scope of the bycatch management strategy based on explicit or otherwise implicit thresholds for acceptable impacts and species-specific fate of the catch

-Identification of contemporary vessel equipment, fishing methods and gear designs that significantly explain catch and survival rates of vulnerable bycatch in the gear type used by the fishery

-Identification of the current government and voluntary industry bycatch management system, including monitoring, control, surveillance and enforcement systems and the legal and regulatory framework. Identification of findings from available performance assessments of the bycatch management framework and of individual bycatch mitigation measures

- Overarching goals, and objectives and performance standards to achieve the goals, for the bycatch management framework that balance stakeholders' competing priorities, and that are specific, measurable, achievable, relevant and time-oriented, covering: (1) Catch and fishing mortality levels or rates of vulnerable bycatch species, (2) level of residual bycatch removals, or otherwise offsets to achieve no net loss or a net gain; (3) acceptable multispecies conflicts; (4) acceptable commercial viability costs; and (5) improvements in other management components (legal, regulatory, monitoring, surveillance, enforcement) 
Table 3 continued

Decision tool step
Selection of subset of comprehensive suite of bycatch mitigation
measures
Ranking of bycatch mitigation methods

Implementation of bycatch Management Strategy Evaluation

Adoption and implementation of bycatch management framework
Output

-Short-list of candidate bycatch mitigation measures of relevance to the fishery

-Matrix of candidate mitigation methods with weights assigned according to: (1) tiers in mitigation and evidence hierarchies, (2) how they meet objectives for mitigation of catch and mortality rates of vulnerable bycatch species, (3) whether they meet objectives on acceptable multispecies conflicts; (4) whether they meet acceptable effects on commercial viability (practicality, safety, economic viability), and (5) enforceability given the capacity of the fisheries management system to conduct compliance monitoring and the effect of crew behavior on performance of the method

-Predict the performance of alternative bycatch management frameworks. Identifying frameworks that are likely to achieve objectives on desired improvements in vulnerable bycatch catch and mortality rates, and on acceptable multispecies conflicts and commercial viability costs, and compare the tradeoffs amongst objectives that each alternative framework is simulated to produce

-Bycatch management plan adopted, with explicit activities, milestones, schedule, budget, responsible parties, process for independent performance assessments and progress reporting. Implementation may result in new and amended: (1) monitoring, surveillance and enforcement systems; (2) legal and regulatory frameworks, including bycatch measures; and (3) industry measures (company policies, code of practice, sustainable seafood sourcing policies and product specs)

\section{Fishery-specific Adaptive Management}

Periodic, impartial performance assessments

Identification of new information and developments (findings from performance assessments, improved evidence, new mitigation approaches, changes in objectives, etc.)
-Performance assessment reports documenting whether the bycatch management program is meeting objectives and milestones

-Revised bycatch management framework and other fisheries management components (legal and regulatory framework; monitoring, surveillance and enforcement systems; industry policies, codes of practice, sustainable seafood sourcing policies, product specs) stakeholders adapt implementation of the tool to suit their specific aims and context.

The tool supports the management of the effects of bycatch at species, stock and population levels. This scope could be expanded to support the management of effects of fisheries on other manifestations of biodiversity, including direct effects on habitat, and indirect, collateral effects such as alterations of evolutionary characteristics of exploited populations through fisheries induced evolution and cascading effects on ecosystem structure and processes manifested through food web links (Baum and Worm 2009;
Estes et al. 2011; Heino et al. 2015). Fisheries management authorities have begun to transition to implementing elements of ecosystem-based fisheries management, with various degrees of success (Pitcher et al. 2009; Gilman et al. 2014). While experiences with operationalizing ecosystem-based fisheries management are relatively recent, there is increasing recognition of the need to manage both direct and broader, collateral responses to fishing pressures (Link and Browman 2017; Link et al. 2020). This decision support framework responds to this need with respect to vulnerable bycatch, a key issue for sustainability 
and for the social license for global fisheries to operate.

Acknowledgements Chrissie Sieben kindly clarified the process for assessments of outcomes on endangered, threatened and protected species against MSC's fisheries standard. Support was provided to EG by the Pew Fellows Program in Marine Conservation at The Pew Charitable Trusts, The Safina Center Fellowship Program and Fondation Ensemble, to HB through an Oxford-NaturalMotion Graduate Scholarship and to TG by the Levine Family Foundation.

Author contributions Study conception: EG; Literature review: All; Manuscript preparation: All.

Funding Support was received by EG from The Pew Charitable Trusts, The Safina Center and Fondation Ensemble, by HB through an Oxford-NaturalMotion Graduate Scholarship, and by TG from the Levine Family Foundation.

Data availability No data were generated or analyzed for the study.

Code availability No code was developed for the study.

\section{Declarations}

Conflicts of interest The authors declare that they have no known conflicts or competing interests that influenced the work reported in this article.

Open Access This article is licensed under a Creative Commons Attribution 4.0 International License, which permits use, sharing, adaptation, distribution and reproduction in any medium or format, as long as you give appropriate credit to the original author(s) and the source, provide a link to the Creative Commons licence, and indicate if changes were made. The images or other third party material in this article are included in the article's Creative Commons licence, unless indicated otherwise in a credit line to the material. If material is not included in the article's Creative Commons licence and your intended use is not permitted by statutory regulation or exceeds the permitted use, you will need to obtain permission directly from the copyright holder. To view a copy of this licence, visit http://creativecommons.org/licenses/by/4.0/.

\section{References}

Abbott J, Anderson J, Campling L et al (2014) Steering the Global Partnership for Oceans. Mar Resour Econ 29:1-16

ACAP (2019) ACAP Review and Best Practice Advice for Reducing the Impact of Demersal Longline Fisheries on Seabirds. Agreement on the Conservation of Albatrosses and Petrels, Hobart, Australia

Amande M, Chassot E, Chavance P, Murua H, Delgado de Molina A, Bez N (2012) Precision in bycatch estimate: the case of tuna purse-seine fisheries in the Indian Ocean. ICES J Mar Sci 69:1501-1510

Arlidge W, Squires D, Alfaro-Shigueto J, Booth H, Mangel J, Milner-Gulland E (2020) A mitigation hierarchy approach for managing sea turtle captures in small-scale fisheries. Front Mar Sci 7:49. https://doi.org/10.3389/fmars.2020. 00049

Australian Antarctic Division (2018) Threat Abatement Plan for the Incidental Catch (or Bycatch) of Seabirds During Oceanic Longline Fishing Operations (2018). Australian Antarctic Division, Department of the Environment and Energy, Australian Government, Canberra

Ayers A, Leong K (2020) Stories of Conservation Success: Results of Interviews with Hawaii Longline Fishers. NOAA Administrative Report H-20-11. National Marine Fisheries Service, Honolulu

Babcock E, Pikitch E, Hudson G (2003) How Much Observer Coverage is Enough to Adequately Estimate Bycatch? Pew Institute for Ocean Science, Miami, and Oceana, Washington, D.C.

Backmann M (2017) What's in a gold standard? In defence of randomised controlled trials. Med Health Care Philos 20:513-523

Baum J, Worm B (2009) Cascading top-down effects of changing oceanic predator abundances. J Anim Ecol 78:699-714

Bayliss H, Beyer F (2015) Information retrieval for ecological syntheses. Res Synth Methods 6:136-148

Bayse S, Kerstetter D (2010) Assessing bycatch reduction potential of variable strength hooks for pilot whales in a western north Atlantic pelagic longline fishery. J N C Acad Sci 126:6-14

Benoit H, Allard J (2009) Can the data from at-sea observer surveys be used to make general inferences about catch composition and discards? Can J Fish Aquat 66:2025-2039

Bianchi G, Skjoldal H (2008) The Ecosystem Approach to Fisheries. Food and Agriculture Organization of the United Nations, Rome

Bigelow K, Kerstetter D, Dancho M, Marchetti J (2012) Catch rates with variable strength circle hooks in the Hawaiibased tuna longline fishery. Bull Mar Sci 88:425-447

Bjerke M, Renger R (2017) Being smart about writing SMART objectives. Eval Program Plann 61:125-127

Bluhm R (2005) From hierarchy to network: a richer view of evidence for evidence-based medicine. Perspect Biol Med 48:535-547

Boesche T (2020) Reassessing quasi-experiments: policy evaluation, induction, and SUTVA. Br J Philos Sci. https://doi. org/10.1093/BJPS/AXZ006

Booth H, Squires D, Milner-Gulland E (2020) The mitigation hierarchy for sharks: A risk-based framework for reconciling trade-offs between shark conservation and fisheries objectives. Fish Fish 2:269-289

Booth H, Arlidge W, Squires D, Milner-Gulland E (2021) Bycatch levies could reconcile trade-offs between blue growth and biodiversity conservation. Nat Ecol. https://doi. org/10.1038/s41559-021-01444-4

Bravington M, Burridge C, Toscas P (2003). Design of Observer Program to Monitor Bycatch Species in the Eastern Tuna and Billfish Fishery. Secretary of the Pacific Community, Noumea, New Caledonia 
Broadhurst MK (2000) Modifications to reduce bycatch in prawn trawls: Review and framework for development. Rev Fish Biol Fisher 10:27-60

Bull J, Suttle K, Gordon A, Singh N, Milner-Gulland EJ (2013) Biodiversity offsets in theory and practice. Oryx 47:369-380

Cannon J, Sousa P, Katara I et al (2018) Fishery improvement projects: Performance over the past decade. Mar Policy 97:179-187

Cao N, Tao T, Moore A et al (2014) Sea snake harvest in the gulf of Thailand. Conserv Biol 28:1677-1687

Capello M, Bach P, Romanov E (2013) Fine-scale catch data reveal clusters of large predators in the pelagic realm. Can J Fish Aquat Sci 70:1785-1791

Casale P, Heppell S (2016) How much sea turtle bycatch is too much? A stationary age distribution model for simulating population abundance and potential biological removal in the Mediterranean. Endanger Species Res 29:239-254

CASS (2021) Guidelines for Supporting Fishery Improvement Projects. Conservation Alliance for Seafood Solutions, Oakland, California, USA

CEBM (2009) Oxford Centre for Evidence-Based Medicine: Levels of Evidence (March 2009). University of Oxford, Oxford

Chaloupka M (2002) Stochastic simulation modelling of southern Great Barrier Reef green turtle population dynamics. Ecol Modell 148:79-109

Chaloupka M, Musick J (1997) Age, growth and population dynamics. Chapter 9. In: Lutz P, Musick J (eds) The Biology of Sea Turtles. CRC Press, USA, CRC Marine Science Series, pp 233-276

Chaloupka M, Pendoley K, Moro D (2012) Control Charts - a robust approach for monitoring endangered species exposure to a major construction project. SPE 156747-PP: 1-8, Society of Petroleum Engineers International Conference on Health, Safety \& Environment, Perth, Australia

Chen H (2015) Practical Program Evaluation: Theory-driven Evaluation and the Integrated Evaluation Perspective, 2nd edn. Sage, Thousand Oaks, California, USA

Cheung W, Lam V, Sarmiento J et al (2010) Large-scale redistribution of maximum fisheries catch potential in the global ocean under climate change. Glob Change Biol 16:24-35

Choi B, Pak A (2005) A catalog of biases in questionnaires. Prev Chronic Dis 2:A13

Christy F (1982) Territorial Use Rights in Marine Fisheries: Definitions and Conditions. FAO Fisheries Technical Paper 227. Food and Agriculture Organization of the United Nations, Rome

Clarke S, Harley S, Hoyle S, Rice J (2013) Population trends in Pacific oceanic sharks and the utility of regulations on shark finning. Conserv Biol 27:197-209

Clarke S, Sato M, Small C et al (2014) Bycatch in Longline Fisheries for Tuna and Tuna-like Species: A Global Review of Status and Mitigation Measures. FAO Fisheries and Aquaculture Technical Paper 588. Food and Agriculture Organization of the United Nations, Rome

Coralie C, Guillaume O, Claude N (2015) Tracking the origins and development of biodiversity offsetting in academic research and its implications for conservation: A review. Biol Conserv 192:492-503
Cox T, Lewison R, Zydelis R, Crowder L, Safina C, Read A (2007) Comparing effectiveness of experimental and implemented bycatch reduction measures: the ideal and the real. Conserv Biol 21:1155-1164

Curtis K, Moore J, Benson S (2015) Estimating limit reference points for western Pacific leatherback turtles (Dermochelys coriacea) in the US West Coast EEZ. PLoS ONE 10:e0136452

Darquea J, Ortiz-Alvarez C, Cordova-Zavaleta F, Medina R, Bielli A, Alfaro-Shigueto J, Mangel J (2020) Trialing net illumination as a bycatch mitigation measure for sea turtles in a small-scale gillnet fishery in Ecuador. Lat Am J Aquat Res 48:446-455

Davidson L, Krawchuk M, Dulvy N (2015) Why have global shark and ray landings declined: Improved management or overfishing? Fish Fish 17:438-458

Dias M, Martin R, Pearmain E et al (2019) Threats to seabirds: A global assessment. Biol Conserv 237:525-537

Die D (2002) Design and implementation of management plans. In Cochran K (Ed) A Fishery Manager's Guidebook Management Measures and their Application. Fisheries Technical Paper 424. Food and Agriculture Organization of the United Nations, Rome

Dillingham P, Fletcher D (2011) Potential biological removal of albatrosses and petrels with minimal demographic information. Biol Conserv 144:1885-1894

Domingo A, Pons M, Jimenez S, Miller P, Barcelo C, Swimmer Y (2012) Circle hook performance in the Uruguayan pelagic longline fishery. Bull Mar Sci 88:499-511

Downes M, Carlin J (2020) Multilevel regression and poststratification versus survey sample weighting for estimating population quantities in large population health studies. Am J Epidemiol 189:717-725

Dulvy N, Ellis J, Goodwin N, Grant A, Reynolds J, Jennings S (2004) Methods of assessing extinction risk in marine fishes. Fish Fish 5:255-276

Dulvy N, Simpfendorfer C, Davison L, Fordham S, Brautigam A, Sant G, Welch D (2017) Challenges and priorities in shark and ray conservation. Curr Biol 27:R565-R572

Dunlop E, Baskett M, Heino M, Dieckmann U (2009) Propensity of marine reserves to reduce the evolutionary effects of fishing in a migratory species. Evol Appl 2:371-393

Eckert S, Gearhart J, Bergmann C, Eckert K (2008) Reducing leatherback sea turtle bycatch in the surface drift-gillnet fishery in Trinidad. Bycatch Communication Newsletter $8: 2-6$

Elfes C, Livingstone S, Lane A et al (2013) Fascinating and forgotten: The conservation status of marine elapid snakes. Herpetol Conserv Biol 8:37-52

Elkington J (1994) Towards the sustainable corporation: winwin-win business strategies for sustainable development. Calif Manag Rev 36:90-100

Emery T, Noriega R, Williams A, Larcombe J (2019) Changes in logbook reporting by commercial fishers following the implementation of electronic monitoring in Australian Commonwealth fisheries. Mar Policy 104:135-145

Environmental Law Institute (2006) The Status and Character of In-Lieu Fee Mitigation in the United States. Environmental Law Institute, Washington, D.C.

Estes J, Terborgh J, Brashares J et al (2011) Trophic downgrading of planet earth. Science 333:301-306 
Fader J, Baird R, Bradford A, Dunn D, Forney K, Read A (2021) Patterns of depredation in the Hawaii deep-set longline fishery informed by fishery and false killer whale behavior. Ecol Appl. https://doi.org/10.1002/ecs2.3682

Fader J, Elliott B, Read A (2021) The challenges of managing depredation and bycatch of toothed whales in pelagic longline fisheries: Two US case studies. Front Mar Sci 8:618031

FAO (1999) International Plan of Action for Reducing Incidental Catch of Seabirds in Longline Fisheries. Food and Agriculture Organization of the United Nations, Rome

FAO (2002) Guidelines for Developing an At-sea Fishery Observer Programme. FAO Fisheries Technical Paper 414. Food and Agriculture Organization of the United Nations, Rome

FAO (2009) Best Practices to Reduce Incidental Catch Seabirds in Capture Fisheries. FAO Technical Guidelines for Responsible Fisheries, Fishing Operations Supplement 2. Food and Agriculture Organization of the United Nations, Rome

FAO (2010) Guidelines to Reduce Sea Turtle Mortality in Fishing Operations. By Gilman, E., Bianchi, G. FAO Technical Guidelines for Responsible Fisheries. ISBN 978-92-106226-5. Food and Agriculture Organization of the United Nations, Rome

FAO (2016) Abandoned, Lost and Discarded Gillnets and Trammel Nets. Methods to Estimate Ghost Fishing Mortality, and Status of Regional Monitoring and Management. FAO Fisheries and Aquaculture Technical Paper 600. Food and Agriculture Organization of the United Nations, Rome

FAO (2019) Joint Analysis of Shark Post-Release Mortality Tagging Results. Workshop Proceedings. Food and Agriculture Organization of the United Nations, Rome

Favaro B, Cote I (2015) Do by-catch reduction devices in longline fisheries reduce capture of sharks and rays? A global meta-analysis. Fish Fish 16:300-309

Finkelstein M, Bakker V, Doak D et al (2008) Evaluating the potential effectiveness of compensatory mitigation strategies for marine bycatch. PLoS ONE 3:e2480

FishChoice (2021) Template Fishery Improvement Project (FIP) Workplan. FishChoice, Fort Collins, USA

Forney K, Kobayashi D, Johnston D, Marchetti J, Marski M (2011) What's the catch? Patterns of cetacean bycatch and depredation in Hawaii-based pelagic longline fisheries. Mar Ecol 32:380-391

Foster F, Bergmann C (2012) Bluefin tuna bycatch mitigation research in the Gulf of Mexico pelagic longline yellowfin tuna fishery In International Symposium on circle hooks in research, management, and conservation abstracts. Bull Mar Sci 88:797

Fu D, Rouz M, Clarke S, Francis M, Dunn A, Hoyle S (2016) Pacific-wide sustainability risk assessment of bigeye thresher shark (Alopias superciliosus). National Institute of Water and Atmospheric Research, Wellington

Fulton E, Smith A, Smith D, Johnson P (2014) An integrated approach is needed for ecosystem based fisheries management: Insights from ecosystem-level management strategy evaluation. PLoS ONE 9:e84242

Gardner B, Sullivan BJ, Morreale SJ, Epperly S (2008) Spatial and temporal statistical analysis of bycatch data: patterns of sea turtle bycatch in the North Atlantic. Can J Fish Aquat Sci 65:2461-2470

Gillet R (2011) Bycatch in Small-scale Tuna Fisheries: a Global Study. FAO Fisheries and Aquaculture Technical Paper No. 560. Food and Agriculture Organization of the United Nations, Rome

Gilman E, Brothers N, Kobayashi D (2005) Principles and approaches to abate seabird bycatch in longline fisheries. Fish Fish 6:35-49

Gilman E, Kobayashi D, Swenarton T et al (2007) Reducing sea turtle interactions in the Hawaii-based longline swordfish fishery. Biol Conserv 139:19-28

Gilman E, Suuronen P, Hall M, Kennelly S (2013) Causes and methods to estimate cryptic sources of fishing mortality. J Fish Biol 83:766-803

Gilman E, Passfield K, Nakamura K (2014) Performance of regional fisheries management organizations: ecosystembased governance of bycatch and discards. Fish Fish $15: 327-351$

Gilman E, Chaloupka M, Merrifield M, Malsol N, Cook C (2016a) Standardized catch and survival rates, and effect of a ban on shark retention, Palau pelagic longline fishery. Aquat Conserv 26:1031-1062

Gilman E, Chaloupka M, Swimmer Y, Piovano S (2016c) A cross-taxa assessment of pelagic longline bycatch mitigation measures: conflicts and mutual benefits to elasmobranchs. Fish Fish 17:748-784

Gilman E, Weijerman M, Suuronen P (2017) Ecological data from observer programs underpin ecosystem-based fisheries management. ICES J Mar Sci 74:1481-1495

Gilman E, Chaloupka M, Dagorn L et al (2019) Robbing Peter to pay Paul: Replacing unintended cross-taxa conflicts with intentional tradeoffs by moving from piecemeal to integrated fisheries bycatch management. Rev Fish Biol Fish 29:93-123

Gilman E, Chaloupka M, Bach P et al (2020) Effect of pelagic longline bait type on species selectivity: A global synthesis of evidence. Rev Fish Biol Fish. https://doi.org/10.1007/ s11160-020-09612-0

Gilman E, Chaloupka M, Peschon J, Ellgen S (2016) Risk factors for seabird bycatch in a pelagic longline tuna fishery. PLoS ONE 11:e0155477

Gjertsen H, Hall M, Squires D (2010) Incentives to address bycatch issues. In: Allen R, Joseph H, Squires G (eds) Conservation and Management of Transnational Tuna Fisheries. Wiley-Blackwell Publishing, Hoboken, pp 225-250

Godin A, Carlson J, Burgener V (2012) The effect of circle hooks on shark catchability and at-vessel mortality rates in longlines fisheries. Bull Mar Sci 88:469-483

Good S, Baker G, Gummery M, Votier S, Phillips R (2020) National Plans of Action (NPOAs) for reducing seabird bycatch: Developing best practice for assessing and managing fisheries impacts. Biol Conserv 247:108592

Gray C, Kennelly S (2018) Bycatches of endangered, threatened and protected species in marine fisheries. Rev Fish Biol Fisheries 28:521-541

Green P, Krieger A, Wind Y (2001) Thirty years of conjoint analysis: Reflections and prospects. Interfaces 31:S56-S73

Griffiths S, Kesner-Reyes K, Garilao C, Duffy L, Roman M (2019) Ecological Assessment of the Sustainable Impact of 
Fisheries (EASI-Fish): A flexible vulnerability assessment approach to quantify the cumulative impacts of fishing in data-limited settings. Mar Ecol Prog Ser 625:89-113

Gudmundssen E, Asche F, Nielsen M (2006) Revenue Distribution through the Seafood Value Chain. Foods and Agriculture Organization of the United Nations, Rome

Haddaway N, Macura B, Whaley P, Pullin A (2018) ROSES RepOrting standards for Systematic Evidence Syntheses: pro forma, flow-diagram and descriptive summary of the plan and conduct of environmental systematic reviews and systematic maps. Environ Evid. https://doi.org/10.1186/ s13750-018-0121-7

Hall MA (1996) On Bycatches Rev Fish Biol Fish 6:319-352

Hall MA, Alverson D, Metuzal K (2000) By-catch: problems and solutions. Mar Pollut Bull 41:204-219

Hall MA, Gilman E, Minami H, Mituhasi T, Carruthers E (2017) Mitigating bycatch in tuna fisheries. Rev Fish Biol Fish 27:881-908

Hall MA, Roman M (2013) Bycatch and Non-tuna Catch in the Tropical Tuna Purse Seine Fisheries of the World. FAO Fisheries and Aquaculture Technical Paper No. 568. Food and Agriculture Organization of the United Nations, Rome

Hall, MA, Nakano H, Clarke S et al (2007) Working with fishers to reduce by-catches. Pp. 235-288 IN Kennelly S (Ed) ByCatch Reduction in the World's Fisheries. ISBN 978-1402060779. Springer, New York

Hall MA (1999) Estimating the ecological impacts of fisheries: what data are needed to estimate bycatches? In Proceedings of the International Conference on Integrated Fisheries Monitoring. Sydney, Australia, 1-5 February 1999, pp. 175-184. Ed. by C. Nolan. Food and Agriculture Organization of the United Nations, Rome, 378 pp.

Hall MA (2015) More on bycatches: Changes, evolution, and revolution. In: G.H. Kruse, H.C. An, J. DiCosimo, C.A. Eischens, G.S. Gislason, D.N. McBride, C.S. Rose, C.E. Siddon (eds.). Fisheries Bycatch: Global Issues and Creative Solutions. http://doi.org/https://doi.org/10.4027/ fbgics.2015.12. Alaska Sea Grant, University of Alaska Fairbanks

Halpern B, Klein C, Brown C et al (2013) Achieving the triple bottom line in the face of inherent trade-offs among social equity, economic return, and conservation. Proc Natl Acad Sci USA 110:6229-6234

Harley S, Pilling G (2016) Potential Implications of the Choice of Longline Mitigation Approach Allowed within CMM 2014-05. WCPFC-SC12-2016/EB-WP-06 Rev 1. Western and Central Pacific Fisheries Commission, Kolonia, Federated States of Micronesia

Harley S, Caneco B, Donovan C, Tremblay-Boyer L, Brouwer S (2015) Monte Carlo Simulation Modelling of Possible Measures to Reduce Impacts of Longlining on Oceanic Whitetip and Silky Sharks. WCPFC-SC11-2015/EB-WP02. Western and Central Pacific Fisheries Commission, Kolonia, Federated States of Micronesia

Hata D (2006) Incidental captures of seabirds in the U.S. Atlantic pelagic longline fishery, 1986-2005. Southeast Fisheries Science Center, National Marine Fisheries Service, Miami, Florida, USA

Hayes K, Hosack G, Lawrence E et al (2019) Designing monitoring programs for marine protected areas within an evidence-based decision-making paradigm. Front Mar Sci 6:746

Heck K, van Belle G, Simberlof D (1975) Explicit calculation of the rarefaction diversity measurement and the determination of sufficient sample size. Ecology 56:1459-1461

Heino M, Pauli B, Dieckmann U (2015) Fisheries-induced evolution. Annu Rev Ecol Evol Syst 46:461-480

Hilborn R (2010) Pretty Good Yield and exploited fishes. Mar Policy 34:193-196

Hilborn R, Walters C (1992) Quantitative Fisheries Stock Assessment: Choice, Dynamics and Uncertainty. Chapman and Hall, London

Hobday A, Hartog J, Timmiss T, Fielding J (2010) Dynamic spatial zoning to manage southern bluefin tuna (Thunnus maccoyii) capture in a multi-species longline fishery. Fish Oceanogr 19:243-253

Hobday A, Smith A, Stobutzki I et al (2011) Ecological risk assessment for the effects of fishing. Fish Res 108:372-384

Huang I, Keisler J, Linkov I (2011) Multi-criteria decision analysis in environmental sciences: ten years of applications and trends. Sci Total Environ 409:3578e3594

ICES (2005) Joint Report of the Study Group on Unaccounted Fishing Mortality (SGUFM) and the Workshop on Unaccounted Fishing Mortality (WKUFM). ICES CM 2005/B:08. International Council for the Exploration of the Sea, Copenhagen

Jones A, Steel D (2018) Evaluating the quality of medical evidence in real-world contexts. J Eval Clin Pract 24:950-956

Kahneman D (2011) Thinking, Fast and Slow. Farrar, Straus; Giroux, New York

Karnad D (2017) Navigating customary law and state fishing legislation to create effective fisheries governance in India. Mar Policy 86:241-246

Kolding J, Bene C, Bavinck M (2014) Small-scale fisheries importance, vulnerability and deficient knowledge. IN Garcia S, Rice J, Charles A (Eds.). Governance for Marine Fisheries and Biodiversity Conservation. Interaction and Coevolution. Wiley-Blackwell, Hoboken, pp. 317-331.

Lawson T (2006) Scientific Aspects of Observer Programmes for Tuna Fisheries in the Western and Central Pacific Ocean. WCPFC-SC2-2006/ST WP-1. Western and Central Pacific Fisheries Commission, Palikir, Federated States of Micronesia

Lawton J, Bignell D, Bolton B et al (1998) Biodiversity inventories, indicator taxa and effects of habitat modification in tropical forest. Nature 391:72-76

Lebon K, Kelly R (2019) Evaluating alternatives to reduce whale entanglements in commercial Dungeness Crab fishing gear. Glob Ecol 18:e00608

Lennert-Cody C (2001) Effects of sample size on bycatch estimation using systematic sampling and spatial post-stratification: summary of preliminary results. IOTC Proceedings 4:48-53

Levrel H, Scemama P, Vaissiere A (2017) Should we be wary of mitigation banking? Evidence regarding the risks associated with this wetland offset arrangement in Florida. Ecol Econ 135:136-149

Lewison R, Crowder L (2003) Estimating fishery bycatch and effects on a vulnerable seabird population. Ecol Appl 13:743-753 
Li Y, Browder J, Jiao Y (2012) Hook effects on seabird bycatch in the United States Atlantic pelagic longline fishery. Bull Mar Sci 88:559-569

Link J, Browman H (2017) Operationalizing and implementing ecosystem-based management. ICES J Mar Sci 74:379-381

Link J, Huse G, Gaichas S, Marshak A (2020) Changing how we approach fisheries: A first attempt at an operational framework for ecosystem approaches to fisheries management. Fish Fish 21:393-434

Little A, Needle C, Hilborn R, Holland D, Marshall C (2015) Real-time spatial management approaches to reduce bycatch and discards: experiences from Europe and the United States. Fish Fish 16:576-602

López-Mendilaharsu M, Giffoni B, Monteiro D et al (2020) Multiple threats analysis for loggerhead sea turtles in the Southwest Atlantic Ocean. Endanger Species Res 41:183-196

Luján J, Todt O (2021) Evidence based methodology: a naturalistic analysis of epistemic policies in regulatory science. Eur J Philos Sci 11:26

Macfadyen G, Huntington T, Cappel R (2009) Abandoned, Lost or Otherwise Discarded Fishing Gear. FAO Fisheries and Aquaculture Technical Paper 523. United Nations Environment Programme and Food and Agriculture Organization of the United Nations, Nairobi and Rome

Mackinson S, Wilson D, Galiay P, Deas B (2011) Engaging stakeholders in fisheries and marine research. Mar Policy $35: 18-24$

Mangi S, Smith S, Catchpole T (2016) Assessing the capability and willingness of skippers towards fishing industry-led data collection. Ocean Coast Manag 134:11-19

Marchionni C, Reijula S (2019) What is mechanistic evidence, and why do we need it for evidence-based policy? Stud Hist Philos Sci A 73:54-63

Martin S, Cambridge T, Grieve C, Nimmo F, Agnew D (2012) An evaluation of environmental changes within fisheries involved in the Marine Stewardship Council certification scheme. Rev Fish Sci 20:61-69

Maseyk F, Barea L, Stephens R, Possingham H, Dutson G, Maron M (2016) A disaggregated biodiversity offset accounting model to improve estimation of ecological equivalency and no net loss. Biol Conserv 204:322-332

Mathur V, Price A, Austin P (2008) Conceptualizing stakeholder engagement in the context of sustainability and its assessment. Constr Manag Econ 26:601-609

Maunder M, Punt A (2004) Standardizing catch and effort data: A review of recent approaches. Fish Res 70:141-159

McCauley D, Pinsky M, Palumbi S, Estes J, Joyce J, Warner R (2015) Marine defaunation: animal loss in the global ocean. Science 347:1255641

McLellan W, Arthur L, Mallette S et al (2015) Longline hook testing in the mouths of pelagic odontocetes. ICES J Mar Sci 72:1706-1713

Mikalsen J, Jentoft S (2001) From user-groups to stakeholders? The public interest in fisheries management. Mar Policy 25:281-292

Milner-Gulland EJ, Garcia S, Arlidge W et al (2018) Translating the terrestrial mitigation hierarchy to marine megafauna by-catch. Fish Fish 19:547-561
Morandin L, O'Hara P (2014) Fish oil disrupts seabird feather microstructure and waterproofing. Sci Total Environ 496:257-263

Morgan R (2012) Environmental impact assessment: The state of the art. 2012. Impact Assess Proj Apprais 30:5-14

MSC (2018) MSC Fisheries Standard. Version 2.01. Marine Stewardship Council, London

MSC (2020) MSC Fisheries Certification Process. Version 2.2. Marine Stewardship Council, London

MSC (2021) The Marine Stewardship Council Annual Report 2019-2020. Celebrating and Supporting Sustainable Fisheries. Marine Stewardship Council, London

Musick J (ed) (1999) Life in the slow lane: ecology and conservation of long-lived marine animals. Symposium 23. American Fisheries Society, Bethesda

Musyl M, Brill R, Curran D, Fragoso N, McNaughton L, Nielsen A, Kikkawa B, Moyes C (2011) Postrelease survival, vertical and horizontal movements, and thermal habitats of five species of pelagic sharks in the central Pacific Ocean. Fish Bull 109:341-361

Nelms S, Alfaro-Shigueto J, Arnould J et al (2021) Marine mammal conservation: Over the horizon. Endanger Species Res 44:291-325

NMFS (2020a) Pacific Island fisheries; sea turtle limits in the Hawaii shallow-set longline fishery. Fed Reg 85:57988-57997

NMFS (2020b) Pacific Island pelagic fisheries; false killer whale take reduction plan; new trigger value for Southern Exclusion Zone closure. Fed Reg 85:81184-81185

NMFS (2019) False Killer Whale Take Reduction Plan. Marine Mammal Commission Meeting, May 21, 2019, Kona, Hawaii. Presentation. https://www.mmc.gov/wp-content/ uploads/False-Killer-Whale-2-GARRETT-2019_05_21_ FKWTRP_MMC_final.pdf. Pacific Islands Regional Office, National Marine Fisheries Service, Honolulu

Norton S, Rodier D, van der Schalie W, Wood W, Slimak M, Gentile J (1992) A framework for ecological risk assessment at the EPA. Environ Toxicol Chem 11:1663-1672

O’Malley M, Townsend K, Hilton P, Neinrichs S, Steward J (2016) Characterization of the trade in manta and devil ray gill plates in China and South-east Asia through trader surveys. Aquat Conserv 27:394-413

Osmundsen T, Amundsen V, Alexander K et al (2020) The operationalization of sustainability: Sustainable aquaculture production as defined by certification schemes. Glob Environ Change 60:102025

Oyanedel R, Gelcich S, Milner-Gulland EJ (2020) Motivations for (non-)compliance with conservation rules by smallscale resource users. Conserv Lett 13:e12725

Pacoureau N, Rigby C, Kyne P et al (2021) Half a century of global decline in oceanic sharks and rays. Nature 589:567-574

Page M, McKenzie J, Bossuyt P et al (2021a) The PRISMA 2020 statement: An updated guideline for reporting systematic reviews. BMJ. https://doi.org/10.1136/bmj.n.71

Page M, Moher D, Bossuyt P et al (2021b) PRISMA 2020 explanation and elaboration: Updated guidance and exemplars for reporting systematic reviews. BMJ. https:// doi.org/10.1136/bmj.n.160

Palomares M, Pauly D (2019) On the creeping increase of vessels' fishing power. Ecol Soc 24:31 
Parga M (2012) Hooks and sea turtles: A veterinarian's perspective. Bull Mar Sci 88:731-741

Pascoe S, Innes J, Holland D et al (2010) Use of incentive-based management systems to limit bycatch and discarding. Int Rev Environ Resour Econ 4:123-161

Pascoe S, Wilcox C, Donlan C (2011) Biodiversity offsets: A cost-effective interim solution to seabird bycatch in fisheries? PLoS ONE 6:e25762

Pereira H, Leadley P, Proença V et al (2010) Scenarios for global biodiversity in the $21 \mathrm{st}$ century. Science 330:1496-1501

Perryman H, Hansen C, Howell D, Olsen E (2021) A Review of applications evaluating fisheries management scenarios through marine ecosystem models. Rev Fisheries Sci Aquaculture. https://doi.org/10.1080/23308249.2021. 1884642

Pfaller J, Chaloupka M, Bolten A, Bjorndal K (2018) Phylogeny, biogeography and methodology: a meta-analytic perspective on heterogeneity in adult marine turtle survival rates. Sci Rep 8:5852

Phillips R, Gales R, Baker G et al (2016) The conservation status and priorities for albatrosses and large petrels. Biol Conserv 201:169-183

Pitcher T, Kalikoski D, Short K, Varkey D, Pramod G (2009) An evaluation of progress in implementing ecosystem-based management of fisheries in 33 countries. Mar Policy 33:223-232

Pomeroy R, Garces L, Pido M, Silvestre G (2010) Ecosystembased fisheries management in small-scale tropical marine fisheries: emerging models of governance arrangements in the Philippines. Mar Policy 34:298-308

Pullin A, Frampton G, Livoreil B, Petrokofsky G (Eds) (2020) Section 5. Conducting a Search. Key CEE Standards for Conduct and Reporting. In Pullin A, Frampton G, Livoreil B, Petrokofsky G (Eds) Guidelines and Standards for Evidence Synthesis in Environmental Management. Version 5.0. Collaboration for Environmental Evidence

Pullin A, Frampton G, Livoreil B, Petrokofsky G (Eds) (2021) Section 3. Planning a CEE Evidence Synthesis. In Pullin A, Frampton G, Livoreil B, Petrokofsky G (Eds) Guidelines and Standards for Evidence Synthesis in Environmental Management. Version 5.0. Collaboration for Environmental Evidence

Punt A, A'mar T, Bond N, Butterworth D, et al (2014) Fisheries management under climate and environmental uncertainty: control rules and performance simulation. ICES J Mar Sci 71:2208-2220

Punt A, Butterworth D, de Moor C, De Oliveira J, Haddon M (2016) Management strategy evaluation: Best practices. Fish Fish 17:303-334

Punt A (2010) Harvest control rules and fisheries management. IN Grafton R, Hilborn R, Squires D, Tait M, Williams M (Eds) Handbook of Marine Fisheries Conservation and Management. Oxford University Press, New York, pp. 582-594

Pynegar E, Gibbons J, Asquith N, Jones J (2021) What role should randomized control trials play in providing the evidence base for conservation? Oryx 55:235-244

Rayns N (2007) The Australian government's harvest strategy policy. ICES J Mar Sci 64:596-598
Reed M, Graves A, Dandy N et al (2009) Who's in and why? A typology of stakeholder analysis methods for natural resource management. J Environ Manage 90:1933-1949

Reinhardt J, Weaver J, Latham P et al (2018) Catch rate and atvessel mortality of circle hooks versus J-hooks in pelagic longline fisheries: A global meta-analysis. Fish Fish 19:413-430

Rindorf A, Dichmont C, Levin P et al (2017) Food for thought: pretty good multispecies yield. ICES J Mar Sci 74:475-486

Roheim C, Bush S, Asche F, Sanchirico J, Uchida H (2018) Evolution and future of the sustainable seafood market. Nature Sustainability 1:392-398

Rosa D, Santos CC, Coelho R (2020) Assessing the effects of hook, bait and leader type as potential mitigation measures to reduce bycatch and mortality rates of shortfin mako: a meta-analysis with comparisons for target, bycatch and vulnerable fauna interactions. ICCAT Collect Vol Sci Papers 76:247-278

Sainsbury K, Punt A, Smith A (2000) Design of operational management strategies for achieving fishery ecosystem objectives. ICES J Mar Sci 57:731-741

Scottish Intercollegiate Guidelines Network Grading Review Group (2001) A new system for grading recommendations in evidence based guidelines. BMJ 323:334-336

Shepperson J, Murray L, Mackinson S, Bell E, Kaiser M (2016) Use of a choice-based survey approach to characterize fishing behaviour in a scall fishery. Environ Model Softw 86:116-130

Skirtun M, Pilling G, Reid C, Hampton J (2019) Trade-offs for the southern longline fishery in achieving a candidate South Pacific albacore target reference point. Mar Policy 100:66-75

Smith A, Fulton E, Hobday A, Smith D, Shoulder P (2007) Scientific tools to support the practical implementation of ecosystem-based fisheries management. ICES J Mar Sci 64:633-639

Smith J, Tommasi D, Welch H et al (2021) Comparing dynamic and static time-area closures for bycatch mitigation: A management strategy evaluation of a swordfish fishery. Front Mar Sci. https://doi.org/10.3389/fmars.2021.630607

SPRFMO (2017) Conservation and Management Measure for Minimising Bycatch of Seabirds in the SPRFMO Convention Area. CMM 09-2017. South Pacific Regional Fisheries Management Organisation, Wellington, New Zealand

Squires D, Garcia S (2018) The least-cost biodiversity impact mitigation hierarchy with a focus on marine fisheries and bycatch issues. Conserv Biol 32:989-997

Squires D, Restrepo V, Garcia S, Dutton P (2018) Fisheries bycatch reduction within the least-cost biodiversity mitigation hierarchy: conservatory offsets with an application to sea turtles. Mar Policy 93:55-61

Squires D, Lent R, Dutton P, Dagorn L, Balance L (2021) Credit systems for bycatch and biodiversity conservation. Front Mar Sci. https://doi.org/10.3389/fmars.2021.613279

Stanley R, McElderry H, Mawani T, Koolman J (2011) The advantages of an audit over a census approach to the review of video imagery in fishery monitoring. ICES J Mar Sci 68:1621-1627

Stegenga J (2014) Down with the hierarchies. Topoi $33: 313-322$ 
Stobutzki I, Miller M, Heales D, Brewer D (2002) Sustainability of elasmobranchs caught as bycatch in a tropical prawn (shrimp) trawl fishery. Fish Bull 100:800-821

Stoll J, Bailey M, Jonell M (2019) Alternative pathways to sustainable seafood. Conserv Lett. https://doi.org/10.1111/ conl.12683

Sutton A (2009) Publication bias. IN Cooper H, Hedges L, Valentine J (Eds) Handbook of Research Synthesis and Meta-Analysis. ${ }^{\text {nd }}$ Edition. Russell Sage Foundation, New York. pp. 435-452

Suuronen P, Pitcher C, McConnaughey R, Kaiser M, Hiddink H, Hilborn R (2020) A path to a sustainable trawl fishery in Southeast Asia. Rev Fish Sci Aquac 28:499-517

Tixier P, Lea M, Hindell M, Welsford D, Maze C, Gourguet S, Arnould J (2021) When large marine predators feed on fisheries catches: Global patterns of the depredation conflict and directions for coexistence. Fish Fish 22:31-53

Tlusty M, Tyedmers P, Bailey M et al (2019) Reframing the sustainable seafood narrative. Glob Environ Change 59:101991

Tolotti M, Filmalter J, Bach P, Travassos P, Seret B, Dagorn L (2015) Banning is not enough: The complexities of oceanic shark management by tuna regional fisheries management organizations. Glob Ecol Conserv 4:1-7

Tourangeau R (2000) Remembering what happened: memory errors and survey reports. In: Stone A, Turkkan J, Bachrach C, Jobe J, Kurtzman H, Cain V (eds) The Science of SelfReport. Lawrence Erlbaum Associates, Mahwah, USA, pp 29-47

Tuck G (2011) Are bycatch rates sufficient as the principal fishery performance measure and method of assessment for seabirds? Aquat Conserv 21:412-422

Uhlmann S, Broadhurst M (2015) Mitigating unaccounted fishing mortality from gillnets and traps. Fish Fish 16:183-229

Vaidyanathan T, Zhang X, Balakrishnan R, Vincent A (2021) Catch and trade bans for seahorses can be negated by nonselective fisheries. Aquat Conserv 31:43-59

van Helmond A, Mortensen L, Plet-Hansen K et al (2020) Electronic monitoring in fisheries: Lessons from global experiences and future opportuntiies. Fish Fish 21:162-189

Wade P (1998) Calculating limits to the allowable humancaused mortality of cetaceans and pinnipeds. Mar Mammal Sci 14:1-37

Wakefield C, Hesp S, Blight S, Molony B, Newman S, Hall N (2018) Uncertainty associated with total bycatch estimates for rarely-encountered species varies substantially with observer coverage levels: Informing minimum requirements for statutory logbook validation. Mar Policy 95:273-282

Wallace B, Kor C, Dimatteo A, Lee T, Crowder L, Lewison R (2013) Impacts of fisheries bycatch on marine turtle populations worldwide: toward conservation and research priorities. Ecosphere 4:1-49

Walsh W, Kleiber P, McCracken M (2002) Comparison of logbook reports of incidental blue shark catch rates by Hawaii-based longline vessels to fishery observer data by application of a generalized additive model. Fish Res 58:79-94

Ward P (2008) Empirical estimates of historical variations in the catchability and fishing power of pelagic longline fishing gear. Rev Fish Biol Fish 18:409-426

Ward-Paige C (2017) A global overview of shark sanctuary regulations and their impact on shark fisheries. Mar Policy 82:87-97

Wattage P, Mardle S, Pascoe S (2005) Evaluation of the importance of fisheries management objectives using choice-experiments. Ecol Econ 55:85-95

WCPFC (2009) Commission for the Conservation and Management of Highly Migratory Fish Stocks in the Western and Central Pacific Ocean. Scientific Committee Fifth Regular Session, Summary Report. Western and Central Pacific Fisheries Commission, Kolonia, Federated States of Micronesia

WCPFC (2018a) Conservation and Management of Sea Turtles. CMM 2018-04. Western and Central Pacific Fisheries Commission, Kolonia, Federated States of Micronesia

WCPFC (2018b) Conservation and Management Measure to Mitigate the Impact of Fishing for Highly Migratory Fish Stocks on Seabirds. CMM 2019-03. Western and Central Pacific Fisheries Commission, Kolonia, Federated States of Micronesia

Werner T, Kraus S, Read A, Zollett E (2006) Fishing techniques to reduce the bycatch of threatened marine animals. Mar Technol Soc J 40:50-68

Wilcox C, Donlan C (2007) Compensatory mitigation as a solution to fisheries bycatch biodiversity conservation conflicts. Front Ecol Environ 5:325-331

Willems T, Depestele J, De Backer A, Hostens K (2016) Ray bycatch in a tropical shrimp fishery: Do Bycatch Reduction Devices and Turtle Excluder Devices effectively exclude rays? Fish Res 175:35-42

Publisher's Note Springer Nature remains neutral with regard to jurisdictional claims in published maps and institutional affiliations. 